\title{
Critical evaluation of infill well placement and optimization of well spacing using the particle swarm algorithm
}

\author{
Evans Annan Boah ${ }^{1}$. $\cdot$ Obed Kwami Senyo Kondo ${ }^{2} \cdot$ Abraham Aidoo Borsah $^{1} \cdot$ Eric Thompson Brantson ${ }^{3}$
}

Received: 28 September 2018 / Accepted: 5 June 2019 / Published online: 12 June 2019

(c) The Author(s) 2019

\begin{abstract}
Optimizing the placement of new wells and well spacing are vital issues in oilfield development. In recent years, the use of particle swarm algorithm (PSA) in many reservoir applications has gained wide acceptance. More importantly, the applications of PSA in determining optimal well placement and well spacing facilitate subsurface development in oil and gas fields. Due to the quest for hydrocarbons, there is the need to maximize oil recovery from petroleum reservoirs. Besides, drilling infill wells are one way to maximize oil recovery from reservoirs. However, the problem of infill well placement is very challenging. This is because many different well placement scenarios must be evaluated when undertaking the optimization program. Most often, the variables that affect the reservoir performance are nonlinearly correlated with some degree of uncertainty. Therefore, the use of computational algorithm has become increasingly common in handling well placement problems. In this paper, PSA has been efficiently used to determine optimal locations of infill wells and their spacings in a synthetic reservoir. The reservoir used in the optimization process is a two-dimensional implicit black-oil model. The objective function in this study is the net present value of the asset (reservoir). For optimal locations, 20-acre, 40-acre and 80-acre spacing were considered for maximization of the objective function. The spacing for optimal locations was varied between wells in the reservoir model. Multiple cases for infill well locations with six existing appraisal wells were considered. After various simulation runs, the optimum locations of infill wells, number of wells and the corresponding well spacings were determined. Consequently, 4 vertical infill wells located at 40 -acre spacing predicted the optimum NPV of $\$ 3.973 \times 10^{9}$. Therefore, this infill design is recommended for field development. Pressure and saturation distribution maps were generated with the maximization of net present value as the objective function. The oil, water and gas productions from the reservoir after infill well drilling were also analyzed. The total oil production after implementation of infill drilling peaked at 44.0 MMSTB, representing $48.31 \%$ recovery. In addition, an uncertainty analysis was performed to evaluate the reservoir performance and its impact on economic parameters that directly affect the net present value. Probability estimates: P10, P50, and P90 were obtained from the uncertainty analysis to provide a basis to estimate the possible net present values and the options for evaluating the different reservoir development scenarios. The major contribution of this study is that a methodology for infill well design has been developed. This will be a useful tool to support petroleum engineers in deciding how to maximize the value of their asset—-the petroleum reservoir.
\end{abstract}

Keywords Reservoir development · Field optimization · Particle swarm algorithm · Infill well drilling · Well placement · Uncertainty analysis

Evans Annan Boah annanevans29@gmail.com

Obed Kwami Senyo Kondo oskwame88@gmail.com

Abraham Aidoo Borsah borsahaidoo@gmail.com

Eric Thompson Brantson ericthompson785@yahoo.com
1 Oil and Gas Engineering Department, All Nations University College, Koforidua, Ghana

2 Mineral Processing Department, BSD Mining Services Limited, PMB, Asiakwa, Ghana

3 Petroleum Engineering Department, University of Mines and Technology, Tarkwa, Ghana 


$\begin{array}{ll}\text { Abbreviations } \\ \text { PSA } & \text { Particle swarm algorithm } \\ \text { NPV } & \text { Net present value } \\ \text { Sor } & \text { Residual oil saturation } \\ \text { TranX } & \text { Transmissibility } \\ \text { PermX } & \text { Horizontal permeability } \\ \text { PermZ } & \text { Vertical permeability } \\ \text { PUNQ-S3 } & \begin{array}{l}\text { Production forecasting for uncertainty } \\ \text { quantification }\end{array} \\ \text { bGA } & \text { Binary genetic algorithm } \\ \text { cGA } & \text { Continuous genetic algorithm } \\ \text { ANN } & \text { Artificial neural network } \\ \text { Poro } & \text { Porosity }\end{array}$

\section{Introduction}

The development of petroleum reservoirs through infill drilling to exploit hydrocarbon reserves not properly drained by existing producing wells is on the growing demand. Determination of locations of infill wells and their optimum spacing, in addition to the maximization of corresponding incremental field production and subsequently the projects profitability, are vital aspects of optimal reservoir management. This is because wide well spacing will consequently cause some of the hydrocarbon bearing sands not to be swept efficiently. Close spacing between wells will cause some of the hydrocarbon bearing sands to be penetrated by more than one well, causing interference and lowering fluid volumes drained by the producing wells. However, the task of optimizing infill well placement is challenging because the prediction of the production capacity of many wells may be required, with each evaluation requiring a simulation run for large or complicated reservoir models. The time for simulation run can sometimes be computationally expensive. The extent of simulations required depends largely on the number of optimization variables, the size of the search space and the type of optimization algorithm employed. Therefore, a more integrated and comprehensive strategy is required than just creating a development plan for effective petroleum reservoir exploitation and management. Different optimization techniques have been utilized to find the optimum well locations in a petroleum reservoir. Among the commonly used well placement algorithms are gradient-free optimization algorithms. One of the gradient-free algorithms is the particle swarm optimization algorithm which has gained wide usage in the industry (Agbauduta 2014). The development of a field involves determining the optimum number, type, and location of new wells that will augment an objective function. The commonly used objective function in addressing well placement optimization problems is the net present value (NPV). Determining the optimal location of wells that ensure high financial returns plays a key role during decision making on reservoir development. Simulations need to be carried out to get the fluid volumes to be used in evaluating the objective function. Optimum well spacing determination is an essential aspect of well placement programs. It is important to ensure some constraints are imposed in the problem formulation. For example, two or more wells cannot be located at the same place or too close to each other to avoid interference and other adverse problems (Onwunalu 2006). This requires the development of a special simulator for well placement and optimization of well spacing in petroleum reservoirs.

Genetic algorithm is considered to be the most commonly used stochastic optimization algorithm employed for well placement and other reservoir management-related applications. The optimization algorithms used for well placement problems are categorized into two domains: global search stochastic algorithms (gradient-free) and gradient-based algorithms (Yeten 2003). The GA is a dynamic computational analog of the process of evolution based on natural selection, where species (solutions) undergo competition to survive. GA illustrates potential solutions to the optimization problem as individuals within a population strive for successive survival. The solution quality (fitness) of the individual evolves as the algorithm iterates significantly (i.e., proceeds from generation to generation). At the end of the simulation, the individual with the highest fitness (best individual) represents the solution to the optimization problem (Goldberg 1989). The two main categories of the GA are the bGA and cGA. Genetic algorithm-based methods have been applied to optimize the locations of both non-conventional wells and vertical wells for solving well spacing optimization problems (Bittencourt and Horne 1997; Artus et al. 2006; Onwunalu 2010). The solutions (fitness) obtained using GA can be improved by combining GA and other optimization algorithms, e.g., Hooke-Jeeves-type of search algorithm, ant colony algorithm, tabu search or polytope algorithm (Bittencourt and Horne 1997; Badru and Kabir 2003; Yeten et al. 2003).

Several researches such as those conducted by Bittencourt and Horne (1997), Guyaguler et al. (2000), Yeten (2003), Onwunalu (2006), Farshi (2008), Abukhamsin (2009) and Emeric et al. (2009) have employed various optimization algorithms for handling intricate optimization issues.

Bittencourt and Horne (1997) developed a hybrid bGA. In their research, they combined GA with the polytope method to benefit from the best features of each method. In the polytope method, optimal solution is achieved by constructing a model that has the number of vertices equal to or more than the dimensionality of the search space. Each vertex is evaluated. The method guided the search space by reflecting the worst point around the centroid of the existing nodes. The approach was able to optimize the placement of horizontal and vertical wells in a real faulted petroleum reservoir by 
optimizing three variables for each well considered: well location, well type (vertical or horizontal), and horizontal well orientation.

Guyaguler et al. (2000) adopted a mixed optimization algorithm and functions such as artificial neural networks and Kriging to serve as proxies to help minimize the cost related with reservoir simulations. The basis for the Kriging algorithm relates to the fact that a certain relationship exists between parameters located in space and time. This relationship is well understood by the algorithm which then tries to obtain the acceptable output. The ANN algorithm works on the principles of biological neurons, which help to establish relations between the inputs and outputs for a series of simulations. The outcome of their study revealed that the Kriging algorithm performed better compared to the ANN algorithm.

Yeten (2003) used bGA to optimize the location, type and trajectory of non-conventional wells. They also developed an optimization tool based on a nonlinear conjugate gradient algorithm to optimize smart well controls. Various helper functions including ANNs and the Hill Climber (HC) were also applied in their research. An experimental design procedure was proposed to measure the effects of uncertainty during the optimization. Finally, they conducted sensitivity analysis in a similar manner to Guyaguler's study.

Onwunalu (2006) applied statistical proxy based on cluster analysis of the GA optimization process for nonconventional wells using Yeten's multilateral well model. The core objective of applying the proxy in their research was to minimize the excessive computational requirements when optimizing under geological uncertainty. The method adopted is similar to the ANN's method in terms of building a store of simulation outputs. The record is then partitioned into clusters containing similar objects. In their study, the objective function of a new scenario can be approximated by assigning it to one of the constructed clusters. In the optimization of individual wells, the proxy provided a close match to the full optimization by simulating only $10 \%$ of the cases. This resulted in a 50\% increment when several nonconventional wells were optimized.

Farshi (2008) conducted a research on well placement optimization. They converted well placement and design optimization framework that was developed by Yeten (2003) from bGA to a real-valued cGA. The results of their study indicated that the cGA provided reliable results when compared to the performance of bGA on the same synthetic models. Moreover, several improvements to the optimization process such as imposing a minimum distance between the various wells and modeling curved wellbores were implemented by Farshi (2008) to obtain better results.

Abukhamsin (2009) conducted a comparative study between the two variants of GA: the bGA and cGA to make a decision on the more robust algorithm to be applied in order to determine optimum well location and well design. The different internal algorithm parameters were tuned by the contribution of adding helper tools and hybrid techniques to the search space for optimum solutions. After performing sensitivity tests on the algorithm, optimum parameters were selected and more in-depth analysis was performed to ascertain an optimum field development plan. In Abukhamsin's study, it was concluded that solutions from different runs had dissimilar well schemes due to the stochastic behavior of the algorithm. However, there were some similarities in well locations. Comparing the bGA and cGA, it was observed that average results from the cGA were slightly higher. This algorithm appeared to be more consistent when several runs were made. Also, analysis of the results showed that better optimization outcomes can be obtained within the shortest possible period of time when dynamic population sizes are utilized. The use of the HC helper tool with the GA delivered efficient final solutions.

Emeric et al. (2009) implemented a genetic algorithm to find the best well configuration for a number of deviated wells. In their study, unrealistic solutions were handled by creating a population-based model that produced reliable results. Unfeasible solutions obtained during the optimization process were also handled by comparing to the base population until a feasible result was attained. The method was implemented with the use of the base population initialized randomly and this yield a better solution.

The review works compared the different algorithms employed for solving well placement problems. Most of these works also considered the optimization of a different number of wells and well types (vertical, deviated, multilateral, etc.) for reservoir development. However, the works did not pay particular and detailed attention to interwell spacing variations and how the variations impact the field's cumulative production, and subsequently the profitability of the development project. In this research, different inter-well spacings were considered in the optimization process.

Despite the usage of GA, the use of PSA is very rare in literature. Therefore, this paper focuses on the use of particle swarm algorithm as the core optimizer to find the best possible locations and spacing of infill wells in a reservoir model for optimal field development. The objective function is the NPV of the asset-petroleum reservoir.

The PSA is applied to a reservoir arbitrary named PUNQ-S3 reservoir to optimize the spacing and locations of infill wells in the reservoir model. Also, the best well configuration for the development of the reservoir model is determined and an uncertainty analysis performed on the reservoir to evaluate different development options.

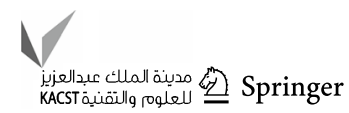


Table 1 Particle swarm algorithm parameters

\begin{tabular}{lc}
\hline Parameters & Values \\
\hline Inertia weight $(\omega)$ & 0.729 \\
Cognitive term $\left(c_{1}\right)$ & 1.492 \\
Social term $\left(c_{2}\right)$ & 1.492 \\
Population size $(\mathrm{Ns})$ & 15.00 \\
\hline
\end{tabular}

\section{Particle swarm algorithm for well placement optimization}

There are many stochastic optimization algorithms of which the particle swarm algorithm is one of those. This algorithm was introduced by Eberhart and Kennedy (1995). The algorithm imitates the actions displayed by animal swarms. The name given to a point found in the search space is referred to as a particle, and a collection of particles per every iteration is referred to as the swarm. Particle positions are altered in the search space until a stopping criterion is satisfied.

Let $y$ represents a probable answer in the search space having $p$-dimensions, thus, $y_{i}(k)=\left\{y_{i, 1}(k), \ldots, y_{i, p}(k)\right\}$ as the position of the $i$ th particle in iteration $k, y_{i}^{\text {pbest }}(k)$ as the previous best solution generated by the $i$ th particle up to iteration $k$ and $y_{i}^{\text {gbest }}(k)$ as the position of the finest particle in the vicinity of particle $y_{i}$ up to iteration $k$. The new position of particle $i$ in iteration $k+1, y_{i}(k+1)$, is calculated by adding a velocity, $v_{i}(k+1)$, to the current position $y_{i}(k)$ (Kennedy and Eberhart 1995; Shi and Eberhart 1998):

$y_{i}(k+1)=y_{i}(k)+v_{i}(k+1)$

where $v_{i}(k+1)=\left\{v_{i, 1}(k+1), \ldots, v_{i, p}(k+1)\right\}$ is the velocity of particle $i$ at iteration $k+1$.

The velocity vector is computed as (Engelbrecht 2005; Shi and Eberhart 1998):

$$
\begin{aligned}
v_{i}(k+1)= & \omega v_{i}(k)+c_{1} D_{1}(k)\left(y_{i}^{\text {pbest }}(k)-y_{i}(k)\right) \\
& +c_{2} D_{2}(k)\left(y_{i}^{\text {gbest }}(k)-y_{i}(k)\right)
\end{aligned}
$$

where $\omega, c_{1}$ and $c_{2}$ represent weights; $D_{1}(k)$ and $D_{2}(k)$ denote matrices with diagonal constituents that are evenly spread arbitrary variables within the range $[0,1]$. The values of $\omega, c_{1}$ and $c_{2}$ used are $\omega=0.729$ and $c_{1}=c_{2}=1.492$. These values were obtained from investigations implemented by Clerc (2006). The new particle velocity, $v_{i}(k+1)$, is added to the present location to get the new vector, $y_{i}(k+1)$, as shown in Eq. (2). Table 1 shows the PSA parameters used in this study.

\section{Particle swarm optimization procedure}

The particle swarm algorithm process is described briefly as follows:
1. Initialization of the values of $c_{1}, c_{2}, \omega, \mathrm{Ns}$ (population size) and $K$ (maximum number of iterations). These values for this study (Table 1) were obtained from Clerc (2006).

2. Initializing the positions of the particle, $y_{i, j}(k)$, with arbitrary components chosen from an even distribution.

Set each velocity component to zero, thus, $v_{i, j}(k)=0$.

3. Evaluate the objective function for all particles that have met the optimization constraints. The objective function in this work was estimated by carrying out a simulation run.

4. Previous best position particles are updated. The best particle in the vicinity is determined for particle $i$. New particle velocities are then calculated, thus, $v_{i}(k+1)$.

5. Particles positions are updated.

6. The objective function is again estimated at these new positions, thus, $f\left(y_{i}(k+1)\right)$.

7. The former finest locations of each particle, $y_{i}^{\text {pbest }}(k)$ is evaluated and if the new objective function value, $f\left(y_{i}(k+1)\right)$, is better than the one at the former finest location, $f\left(y_{i}^{\text {pbest }}(k)\right)$, the new objective function value and particle positions are accepted.

8. Steps $5-7$ are repeated until the maximum number of iterations is reached, but the objective function value and particle positions are changed only when the new ones are better than the ones obtained in step 7 .

9. The algorithm terminates when the maximum number of iteration is reached.

\section{Evaluation of objective function}

One important component in every optimization process is the evaluation of an objective function which is either, minimized or maximized during the optimization process. Decisions in an optimization process are based on the outcome of an evaluated objective function. The objective function used in this work is the NPV. The NPV is simply discounting the cash flow to the beginning of the project. Evaluating the NPV during the optimization process requires a simulation run. The Sensor6K simulator (Coats 2013) was used for the simulations. The NPV is evaluated from the fluid productions obtained after each simulation run. These are presented as follows:

$\mathrm{NPV}=\sum_{t=1}^{k} \frac{\mathrm{NCF}_{t}}{(1+r)^{t}}-C_{\mathrm{CAPEX}}$

$C_{\mathrm{CAPEX}}=C_{\mathrm{f}}+N_{\text {prod }} C_{\text {prod }}+N_{\mathrm{inj}} C_{\mathrm{inj}}$

where $C_{\mathrm{f}}$ is the facilities installation cost, $N_{\text {prod }}$ is the number of producer(s), $N_{\text {inj }}$ is the number of injector(s), $C_{\text {prod }}$ is the cost of producer and $C_{\mathrm{inj}}$ is the cost of an injector.

The net cash flow at time $t, \mathrm{NCF}_{t}$, is computed using: 
Table 2 Economic parameters for NPV computation

\begin{tabular}{ll}
\hline Parameters & Values \\
\hline$C_{\mathrm{f}}$ & $\$ 50 \times 10^{6}$ \\
$C_{\text {prod }}$ & $\$ 4.0 \times 10^{6}$ \\
$C_{\text {inj }}$ & $\$ 4.0 \times 10^{6}$ \\
$C_{\mathrm{op}}$ & $\$ 11.5 / \mathrm{STB}$ of oil \\
$C_{\mathrm{wp}}$ & $\$ 7 / \mathrm{STB}$ of water \\
$C_{\mathrm{wi}}$ & $\$ 10 / \mathrm{STB}$ of water \\
$P_{\mathrm{o}}$ & $\$ 44 / \mathrm{STB}$ of oil \\
$P_{\mathrm{g}}$ & $\$ 3.57 / \mathrm{MSCF}$ \\
$r$ & 0.10 \\
\hline
\end{tabular}

$\mathrm{NCF}_{t}=R_{t}-E_{t}$

where $R_{t}$ and $E_{t}$ represent the revenue $(\$)$ and operating expenses (\$), respectively, at time $t$. The revenue and operating expenses depend on the fluid production volumes at time $t$ :

$R_{t}=P_{\mathrm{o}} Q_{t}^{\mathrm{o}}+P_{\mathrm{g}} Q_{t}^{\mathrm{g}}$

where $P_{\mathrm{o}}$ and $P_{\mathrm{g}}$ represent the oil price $(\$ / \mathrm{STB})$ and gas price (\$/MSCF), respectively; and $Q_{t}^{\mathrm{o}}$ and $Q_{t}^{\mathrm{g}}$ represent the total volumes of oil (STB) and gas (MSCF) produced, respectively, over the time step.

The operating expense at time $t, E_{t}$, is computed as:

$E_{t}=C_{\mathrm{wp}} Q_{t}^{\mathrm{w}}+C_{\mathrm{wi}} Q_{t}^{\mathrm{wi}}+C_{\mathrm{op}} Q_{t}^{\mathrm{o}}$

where $C_{\mathrm{wp}}$ represents water production and treatment costs (\$/STB), $C_{\mathrm{wi}}$ represents water injection cost, $C_{\mathrm{op}}$ represents cost of operation per STB of oil and $Q_{t}^{\mathrm{w}}$ represent the total volumes of water produced (STB) at time $t, Q_{t}^{\text {wi }}$ represent the total volumes of water injected (STB) at time $t . P_{\mathrm{o}}, P_{\mathrm{g}}$, $C_{\mathrm{wp}}, C_{\mathrm{wi}}$ and $C_{\mathrm{op}}$ are taken to be constant in time, in all cases. Table 2 lists the economic parameters used in the computation of the objective function, NPV.

\section{Methodology}

This research presents a systematic methodology to evaluate potential locations and spacing of infill wells for optimization purpose. Development of a MATLAB program is carried out for the PSA for well placement with respect to maximization of the objective function, i.e., NPV. The scope of this study does not include creating an actual reservoir development strategy that can be implemented in this field of interest. Rather, it involves evaluating several reservoir development scenarios and using reservoir simulation approach to maximize the profitability of the studied reservoir. The optimization procedure involved evaluating initial production with existing wells subject to minimum oil rate, maximum water cut, maximum gas-oil ratio and minimum bottom-hole pressure constraints. The resulting fluid productions obtained from multiple simulation runs are used to compute the NPV. The analysis of cases to select the best alternative for optimal reservoir development was made. This included infill well drilling after the initial production period under three conditions: type of wells, the number of wells and spacing between the drilled wells. 20-, 40-, and 80-acre well spacing arrangements were considered for drilling of new infill wells. Three and four vertical infill wells were initiated for different simulation runs. The spacing for the infill wells was varied in the reservoir model. Initially, the six existing wells were produced for 15 years. Afterward, a production forecast is then carried out for an additional 15 years making a total of 30 years continuous production. Computational cost analysis is performed to assess the computational time for the various case runs. The next stage involved carrying out uncertainty analysis on the reservoir using hypothetical parameters. The uncertainty analysis provided the basis for estimation of the net present value and also evaluate the risk associated with the reservoir development.

Finally, the results obtained were analyzed, discussed and conclusions drawn. Tools used in this research included: MATLAB and Sensor 6K simulation tools. MATLAB was used to develop a program for the particle swarm optimization algorithm. The Sensor6K tools were used to run simulations for a series of cases considered to achieve optimal well locations and spacing of infill wells. It was also used for carrying out uncertainty analysis for the different scenarios. Figure 1 presents a flowchart for methodology.

\section{Reservoir model description}

The reservoir used in this study is the PUNQ-S3 reservoir model. This reservoir model is a real field which was operated by Elf Exploration and Production. This reservoir model was categorized as a small-size engineering reservoir model. Grid dimensions in the model are $19 \times 28 \times 5$. The size of each grid in the $x$ and $y$ directions are approximately 200 $\mathrm{ft}$, respectively, and approximately $52 \mathrm{ft}$ for each grid in the $z$-direction. There are five layers in the reservoir model. The gas-oil and oil-water contacts are located at $7726.4 \mathrm{ft}$ and $7856.3 \mathrm{ft}$ in the reservoir, respectively. The reservoir has a strong aquifer support connected to the northern and western sides. It has a fault at the eastern and southern parts. There is a gas cap located at the top of the dome-shaped structure. There are six existing producing wells in the reservoir model but no injection wells as a result of the existence of a strong aquifer. During the first 8 years (0-2936 days), well PRO-1, PRO-3 have a gas breakthrough; PRO-4 has water breakthrough; no other well had gas or water breakthrough. The corner point geometry was used in the construction of

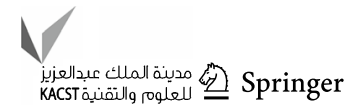


Fig. 1 Flowchart of methodology used for the optimization process

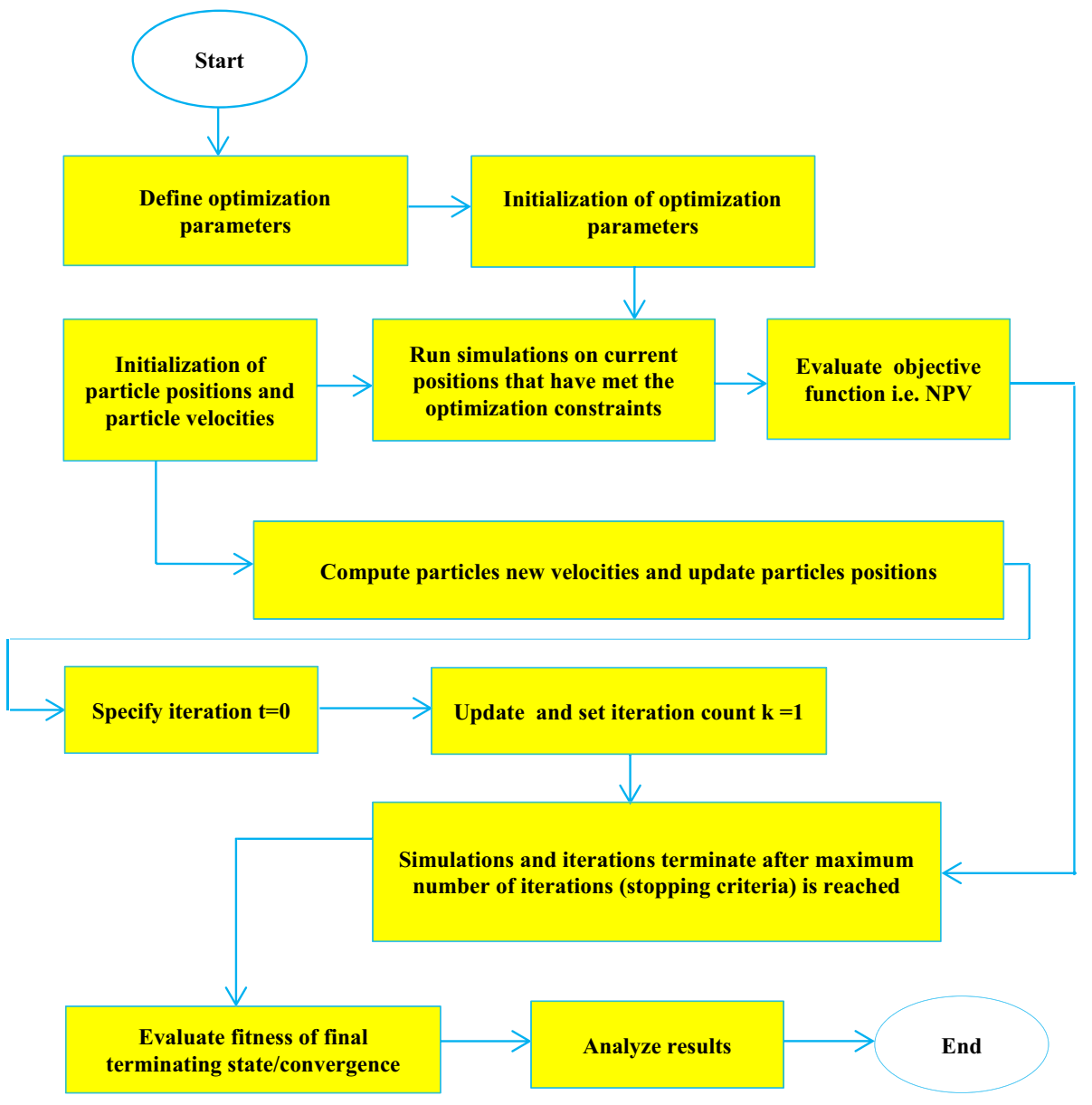

the reservoir model. Detailed analysis was carried out to study the application of infill well placement optimization in the PUNQ-S3 reservoir model. The objective is to find the optimal locations for drilling infill wells, with already six producing wells in the reservoir model, while considering the uncertainties associated with the reservoir and economic parameters. Figure 2 shows the contours for oil saturation zones with locations of appraisal wells.

\section{Permeability distribution model}

Permeability anisotropy predicts reservoir performance and the geometry (shape) of the drainage area surrounding every wellbore including its storage effect. The possibility of obtaining higher permeability values in one direction can lead to formation of elliptical well drainage area. On this note, the permeability distribution pattern in the vertical and lateral direction for layers of the reservoir model was mapped and analyzed. Considering the permeability distribution of the model, one can determine optimum well locations trivially. Detailed analysis was performed for layers 3 and 4 where the infill wells were located. We assumed isotropic permeability condition in the lateral direction of the

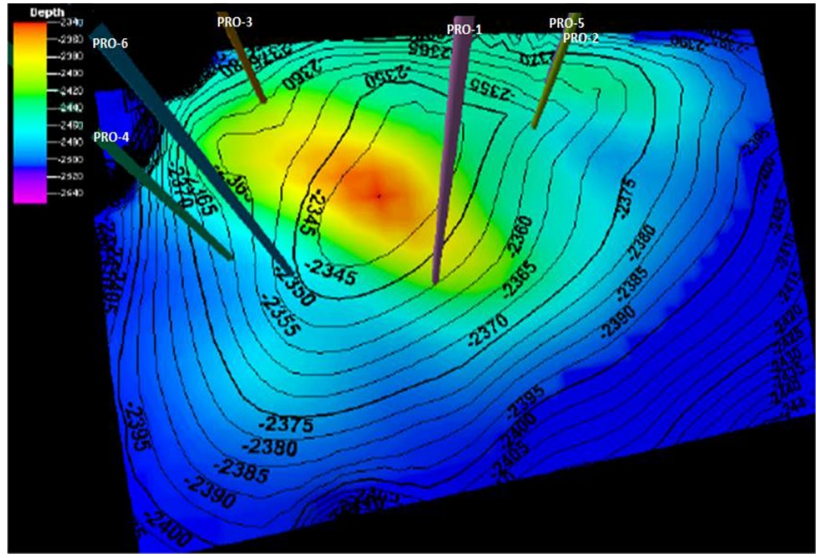

Fig. 2 Contour map showing oil saturation at various depths with location of appraisal wells

reservoir model, thus, $k_{x}=k_{y}$. However, the permeability distribution of the reservoir would be the same regardless of the infill design. The essence of this task is to provide information on the spatial variations of permeability in the reservoir layers where infill well placement was performed. From the 
Fig. 3 Directional permeability distribution maps for various layers of the reservoir model

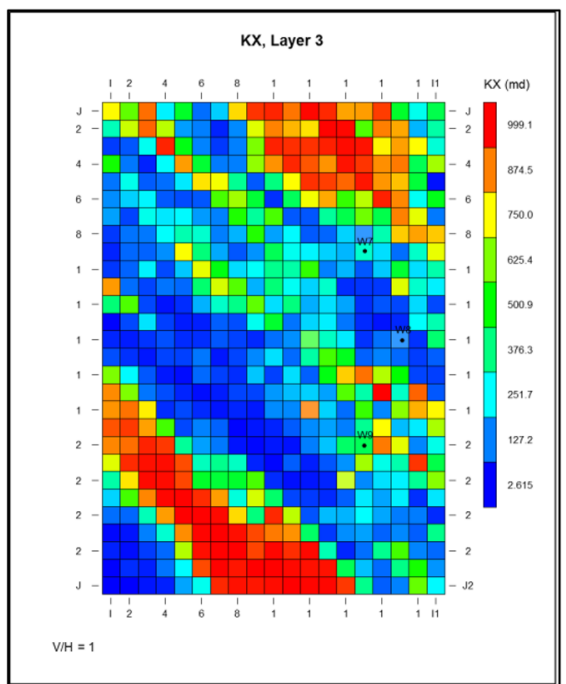

(a) Lateral permeability map for Layer 3

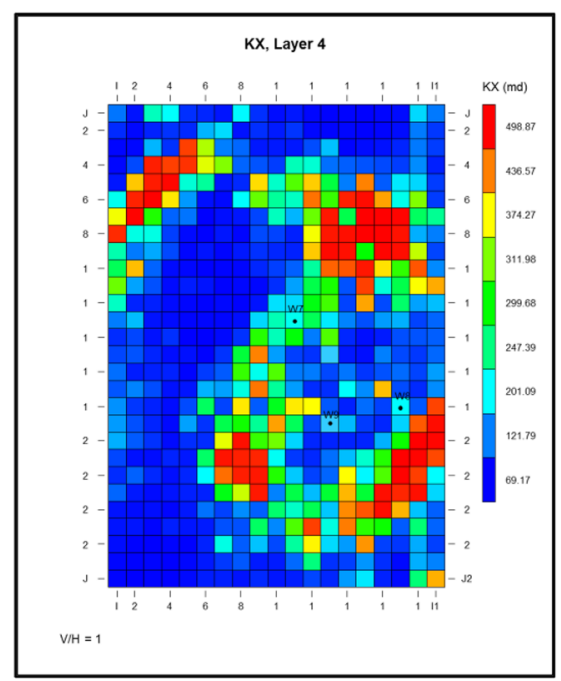

(c) Lateral permeability map for Layer 4

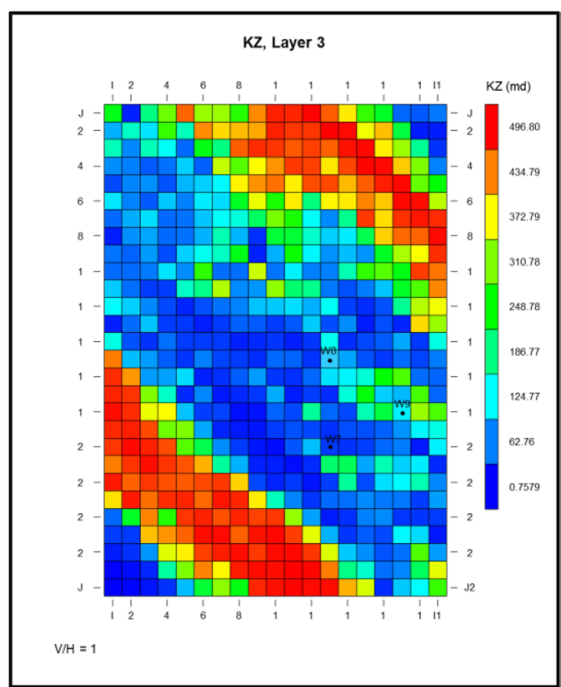

(b) Vertical permeability map for Layer 3

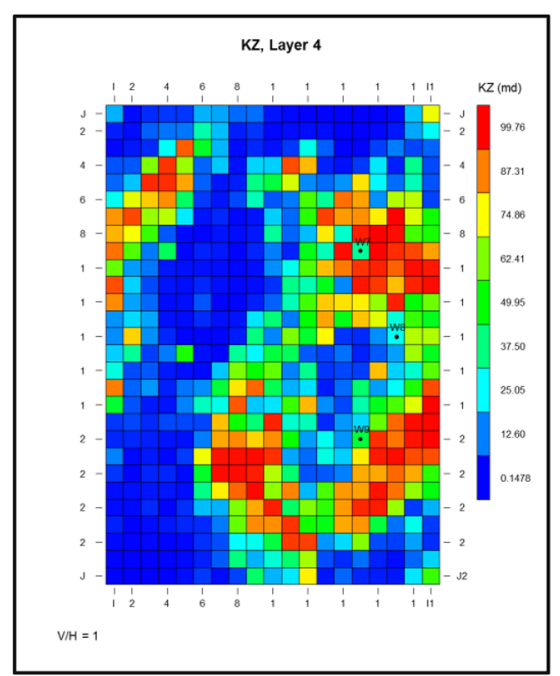

(d) Vertical permeability map for Layer 4 results, higher permeability values were observed in the vertical and lateral directions for layers of the reservoir model as shown in Fig. 3. The horizontal permeability values for both layers $(3 \& 4)$ ranged between $2.625-999.10 \mathrm{mD}$ and $69.17-498.87 \mathrm{mD}$, whereas vertical permeability values fell between $0.7579-496.80 \mathrm{mD}$ and $0.1478-99.76 \mathrm{mD}$, respectively. Table 3 shows the summary of history data used. Initial conditions of reservoir used for the optimization process is also presented in Table 4.

\section{Summary of optimization process, results and discussion}

Disseminating acceptable location to place wells in a reservoir is a critical issue in oil and gas field development. The
Table 3 Ranges of reservoir history data used for the well optimization process

\begin{tabular}{|c|c|c|c|}
\hline Parameters (units) & Minimum & Average & Maximum \\
\hline $\begin{array}{l}\text { Threshold pressure gradient (psia/ } \\
\mathrm{ft} \text { ) }\end{array}$ & 284 & 1288 & 1958 \\
\hline Reservoir temperature $\left({ }^{\circ} \mathrm{F}\right)$ & 165.7 & 168 & 198.6 \\
\hline $\begin{array}{l}\text { Bottom-hole flowing pressure } \\
\text { (psia) }\end{array}$ & 2080 & 2885 & 3317.7 \\
\hline $\begin{array}{l}\text { Cumulative oil production } \\
\text { (MMSTB) }\end{array}$ & 23.5 & 25.8 & 28.7 \\
\hline Cumulative gas production (BCF) & 10.87 & 13.10 & 15.53 \\
\hline $\begin{array}{l}\text { Cumulative water production } \\
\text { (MMSTB) }\end{array}$ & 0.0452 & 0.0599 & 0.0879 \\
\hline Recovery efficiency, RF (\%) & 22.72 & 22.93 & 32.0 \\
\hline
\end{tabular}


Table 4 Initial conditions of the reservoir

\begin{tabular}{ll}
\hline Conditions & Values \\
\hline Initial oil-in-place & 109.276 MMTSB \\
Total recovery after initial production period & 25.049 MMSTB \\
Recover factor & $22.93 \%$ \\
Initial years of production & 15 years \\
Number of existing wells & 6 \\
Approximate initial well spacing(s) & Varied between \\
& 80 and 130 acres \\
\hline
\end{tabular}

optimization process is subject to the fulfillment of certain constraints. Therefore, to achieve the aim of this paper, we focused on maximization of the net present value as the objective function for the case study considered. The PSA was implemented to identify the optimal well locations and spacing between the wells. Several development scenarios were analyzed for the simulated case runs before selecting the best alternative plan for reservoir development. First, the constraints are presented. This is followed by the discussion of the development scenarios examined in this study.

\section{Constraints developed for the well placement process}

1. The minimum inter-well spacing is one important consideration in this work. Infill wells cannot be placed at locations occupied by existing wells and cannot be placed at locations where another infill well has already been placed. Another consideration is to ensure that wells are placed at an appreciable distance away from each other to avoid interference between wells and other adverse drainage problems.

2. The proposed locations for the infill wells should have an average pressure which is more than the threshold pressure of the reservoir. This is done to ensure that the proposed locations have enough pressure (reservoir energy) to support fluid production.

3. Infill wells must be placed in areas in the reservoir where there is enough oil saturation. Locations for infill drilling should have oil saturation $\left(S_{\mathrm{o}}\right)$ which is more than the residual oil saturation $\left(S_{\mathrm{or}}\right)$, plus some allowable percentage margin. The margin used in this study is $10 \%$. That is, $S_{\mathrm{o}} \geq S_{\mathrm{or}}+0.1$. The areas that do not meet the constraint was not included in the search space.

4. Infill wells are placed only in active blocks in the reservoir model. There are 2660 blocks in the reservoir model of which 1761 are active blocks.

5. Infill wells are placed at a fair distance away from the reservoir boundaries, the aquifer, and the oil-water inter- face. The infills wells were produced at constant rate and bottom-hole pressure of $1800 \mathrm{stb} /$ day and $3317.7 \mathrm{psia}$, respectively.

\section{Computational cost analysis for the optimization process}

Computational cost analysis was performed to evaluate the computational time for the various simulation runs adopted. The linearization schemes for PSA and implicit pressure, explicit saturation (IMPES) models were compared in terms of their numerical convergence by constantly monitoring the computational times. The models were specified within tolerance limit considering two cases of infill well drilling which captured both pressure and saturation distributions. 100 iterations were initialized for each of the two scenarios considered for well placement optimization using the particle swarm algorithm. The PSA models exhausted 2 min $18 \mathrm{~s}$ CPU time for the optimization process. The iterative solution from the PSA models converged rapidly from 62nd to 70th iteration with repeated solutions. Hence, computational cost is minimized due to its faster convergence rate. Again, the PSA model revealed a stabilized numerical solution within acceptable tolerance limit compared to the IMPES models. The IMPES models utilized 4 min $57 \mathrm{~s}$ simulation time to reach terminating state, exhausting much run time. It can be inferred that the IMPES models required much computational time and search space as the simulation progresses. Therefore, it can be stated that computational time for the IMPES models increased while CPU time for the PSA decreased within the defined time steps.

\section{Pressure and saturation distribution maps for initial production period with existing wells}

Pressure is considered the primary energy that supports production of fluids from a reservoir. Therefore, it is essential to quantify and monitor pressure variations in reservoir development projects. In this paper, we present pressure and saturation distribution maps generated after the initial production with existing wells in the reservoir model. The results obtained were used to identify potential areas in the reservoir that have enough pressure and oil saturations suitable for infill well placement. These existing wells have been used to produce the reservoir for a period of 15 years. A minimum pressure of 1800 psia was used as the threshold pressure to identify locations that have the energy to support the production of the reservoir.

The hydrocarbon pore volumes associated with oil saturations for the two-dimensional synthetic reservoir model is shown in Fig. 4. It represents areas where there are producible concentrations of oil in the reservoir model. Again, high permeable layers of the reservoir were considered to 
Fig. 4 Hydrocarbon pore volume map showing oil saturation at various depths

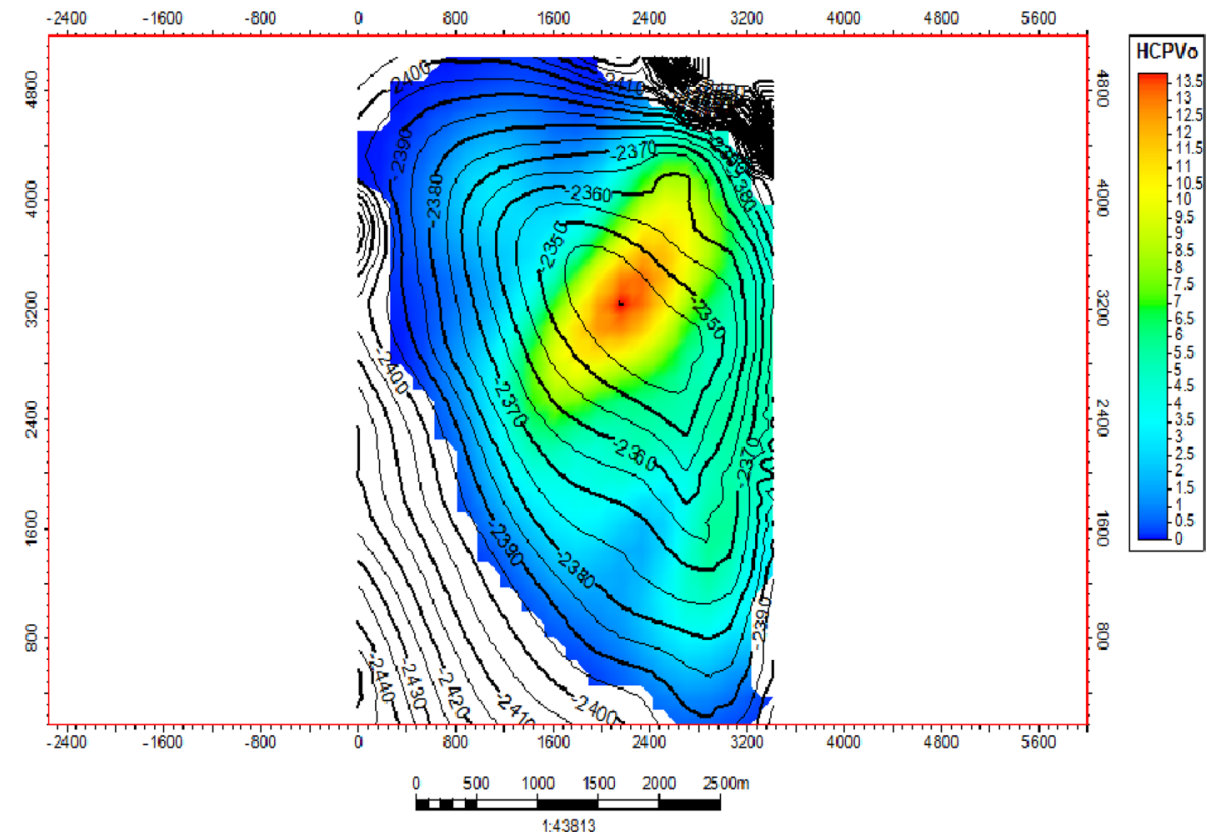

locate optimal wells due to the fact that more oil can be extracted from those layers. This provided the guide in our well placement optimization process. To start with, we present the pressure distribution maps for layers $(3 \& 4)$ in the reservoir produced with existing wells as shown in Fig. 5. The pressure distribution maps in Fig. 5 were used to identify high-pressure areas in the reservoir model. This was done to select areas in the reservoir with the adequate pressure support which can be considered for well placement. In this manner, the feasible areas in the reservoir model with an average pressure equal or above the reservoir threshold pressure, (i.e., $1800 \mathrm{psia}$ ) were considered. These areas were included in the computational search space to place infill wells. This was incorporated in the optimization process such that the optimizer searches for only feasible areas in the reservoir with pressure equal or above the reservoir threshold pressure. Moreover, locations with inadequate pressure support (reservoir energy) were considered non-feasible for well placement. The distribution maps presented in Fig. 5 have pressures above the threshold point. However, there was an aquifer connected to the northern and western sides of the reservoir model. This is shown as the red-colored areas in Fig. 5. These areas were considered as non-feasible for infill drilling, although they met the pressure constraint, they failed to meet the saturation constraint.

Making a decision on where to locate infill wells in a reservoir based on pressure distribution alone is not enough to result in optimum hydrocarbon recovery. This is because there are areas in the reservoir with very low oil and high water saturations which can result in low hydrocarbon recovery. In order to satisfy the constraints to achieve better fluid recovery in the reservoir, fluid saturation maps were generated for the different layers in the reservoir, produced with existing wells as shown in Fig. 6. As a rule-based constraint, simulating potentially known poor locations was avoided. For this reason, the search space was conditioned to select areas with adequate oil and low water saturations for infill well placement. Screening individual layers of the reservoir helped to define the search domain to carry out the optimization process.

However, sections of the reservoir with strong aquifer support are considered water saturated zones. These areas did not meet the saturation constraint and were treated as non-feasible locations. Therefore, these areas were eliminated from the search space as shown in Fig. 6.

\section{Implementation of the particle swarm algorithm}

The particle swarm algorithm is a population-based algorithm that mimics the movement of a swarm of animals. Basically, the algorithm has two main equations. These are the particle velocity formulation which can be found in Eq. (1) and particle position vector represented in Eq. (2), that track the movement of particles within the swarm (population size) until a stopping criterion is met. The critical evaluation factors used in our maximization process include the cumulative oil production, cumulative gas production and cumulative water production. The optimization process together with the simulations was programmed in MATLAB. Initially, detailed screening of the reservoir was done to know the suitable areas where infill wells can be located in the model. Afterward, all the necessary constraints were defined. The optimization and well placement process were carried out. The number of infill wells and their spacings were varied

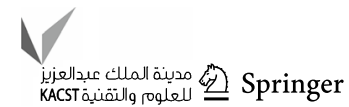


Fig. 5 Pressure distribution maps for various layers of the reservoir with existing wells (15 years simulated production period)

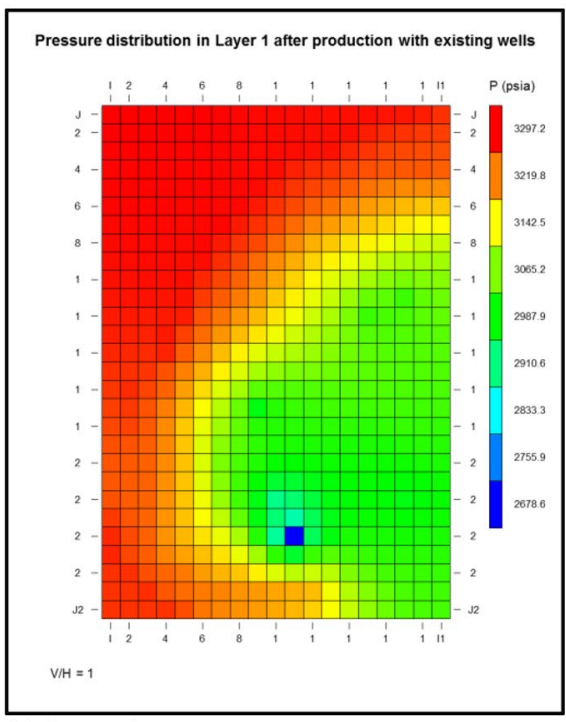

(a) Layer 1

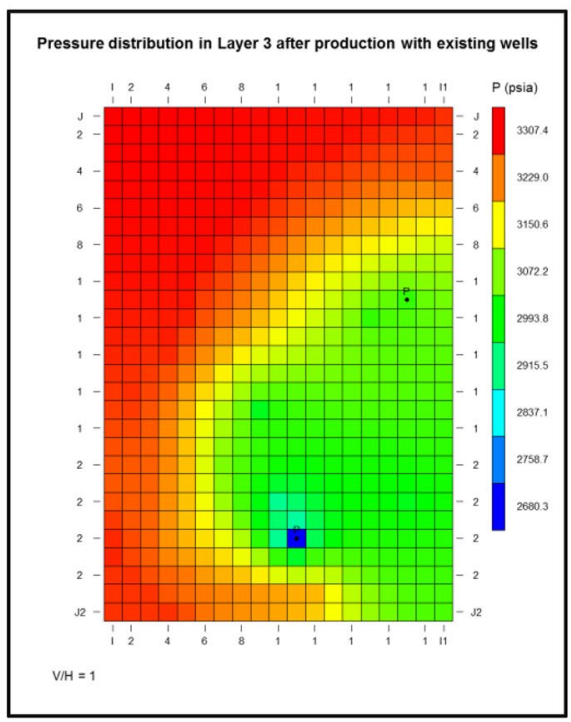

(c) Layer 3

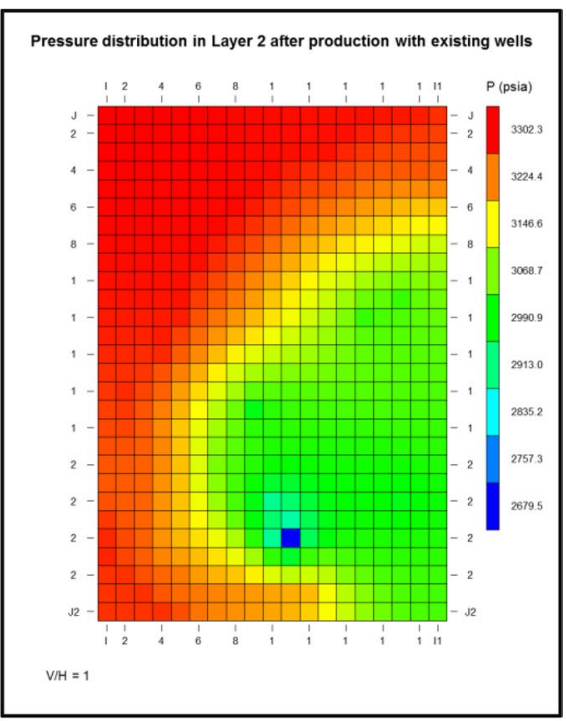

(b) Layer 2

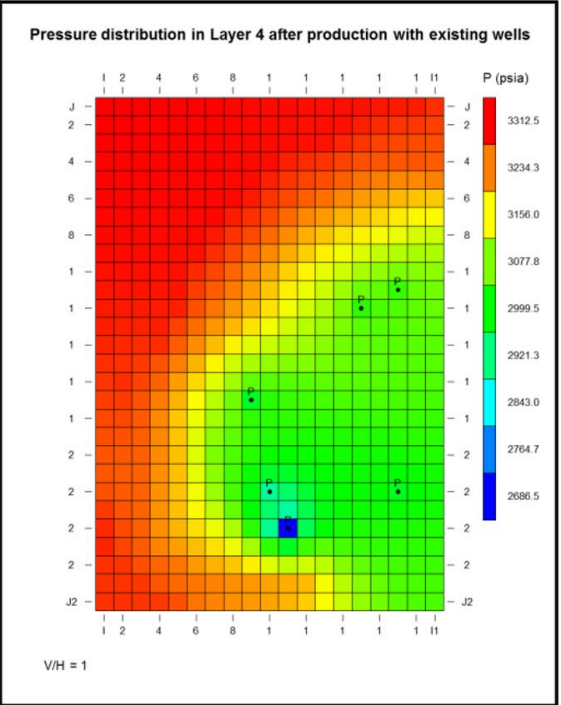

(d) Layer 4 in the computational search space during the optimization. Three outcomes were obtained after multiple runs for the optimization process. This is outlined as follows: (1) The optimized locations of infill wells in the reservoir model, (2) The net present value that corresponds to these optimized locations and (3) An output file from which the cumulative fluid production versus time can be obtained. The detailed procedure for the optimization process is captured in Fig. 1.

\section{Case studies}

Regarding infill design for oilfield development, the wells cannot be placed at the same locations. Therefore, we proposed an approach to finding optimal well locations and spacing to make infill drilling decision within well-defined pressure and saturation zones in a reservoir model. The optimized locations of the wells were estimated using the particle swarm optimization algorithm. In these examples, we maximize NPV by optimizing vertical infill wells in a two-dimensional synthetic reservoir model for proposed field development. The approach was applied to two different reservoir development scenarios. The amount of fluid produced in each case was compared to the well spacing for each infill pattern. Several simulation runs were carried out using the optimization program to evaluate different well spacings with a certain number of wells. The evaluation aimed at finding the optimal location and spacing of infill wells. Different well patterns: 20 acre, 40 acre, and 80 acre were considered. However, the case study focused 
Fig. 6 Saturation distribution maps for various layers of the reservoir with existing wells (15 years simulated production period)

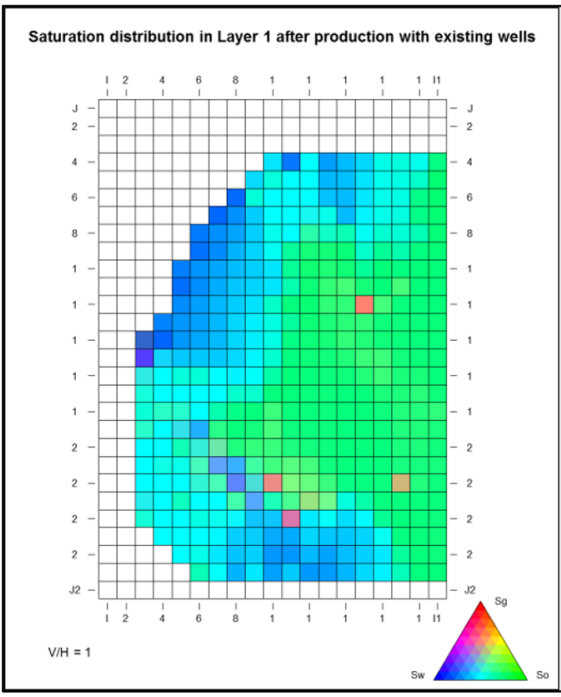

(a) Layer 1

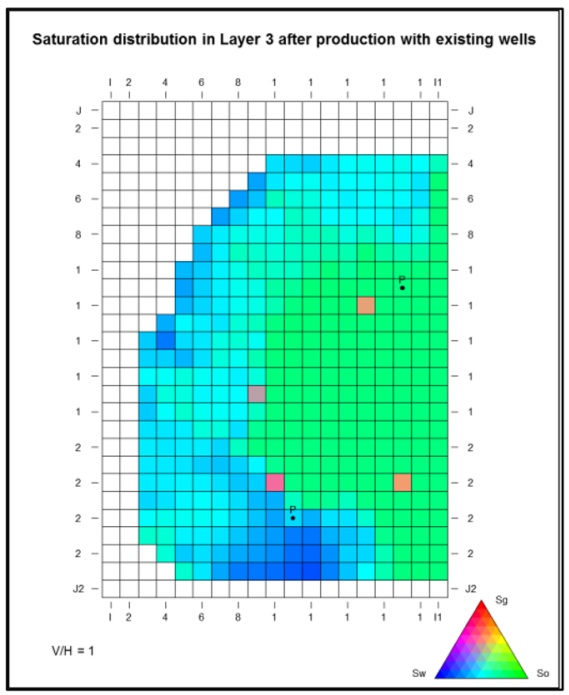

(c) Layer 3

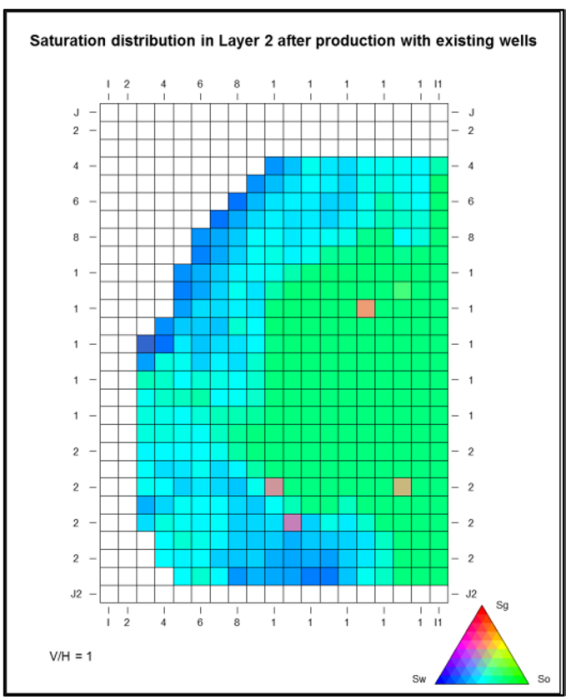

(b) Layer 2

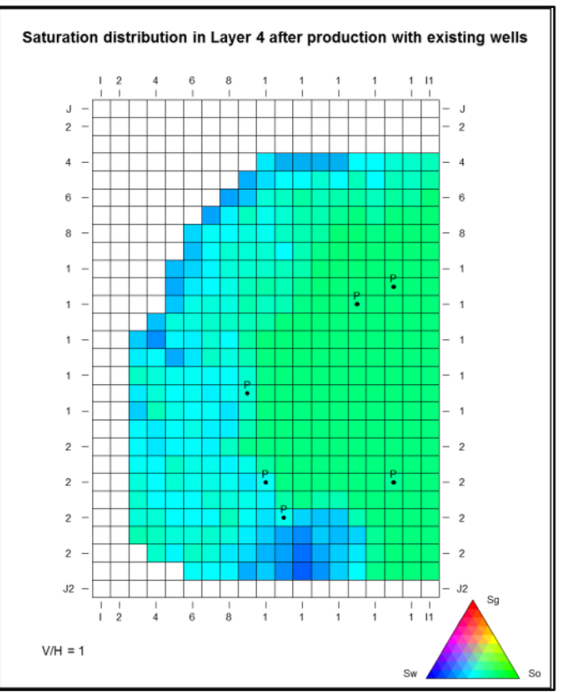

(d) Layer 4 on drilling three and four infill wells in the model. In each of the spacing, a certain number of wells were drilled for different development scenarios. Initially, six existing wells were completed in the reservoir. These existing wells were first produced for 15 years. Then, followed by an additional 15 years of production forecast combined in all cases. Finally, feasibility studies of the infill wells were made taking into consideration the total production of each case to find the best infill candidates with the highest NPV. Figure 7 shows the locations of existing wells in the reservoir model.

\section{Case 1: 20-, 40- and 80-acre spacing for 3 vertical infill wells}

The performance and economic feasibility of different well placement scenarios were evaluated and their optimum design determined. In case 1, three vertical infill well drilling scenario was considered for development of the reservoir. The model operates under bottom-hole pressure and production rate constraints of $3317.7 \mathrm{psia}$ and $1800 \mathrm{stb} / \mathrm{day}$, respectively. The optimum drilling location of three vertical wells is investigated considering 15 years of production. The results of the optimized well locations, as well as the net present values of the petroleum asset, are presented. The optimized locations of the infill wells at different spacings: 20 acre, 40 acre, and 80 acre are shown in Fig. 8. Subsequently, the pressure and saturation distribution maps for the optimized well locations after the three vertical infill drilling are presented in Figs. 9 and 10. It is interesting to note that the infill wells considered in case 1 are located in high saturation zones, ranging between 33.98 and $42.17 \%$ in the reservoir model. These are potential locations for drilling 


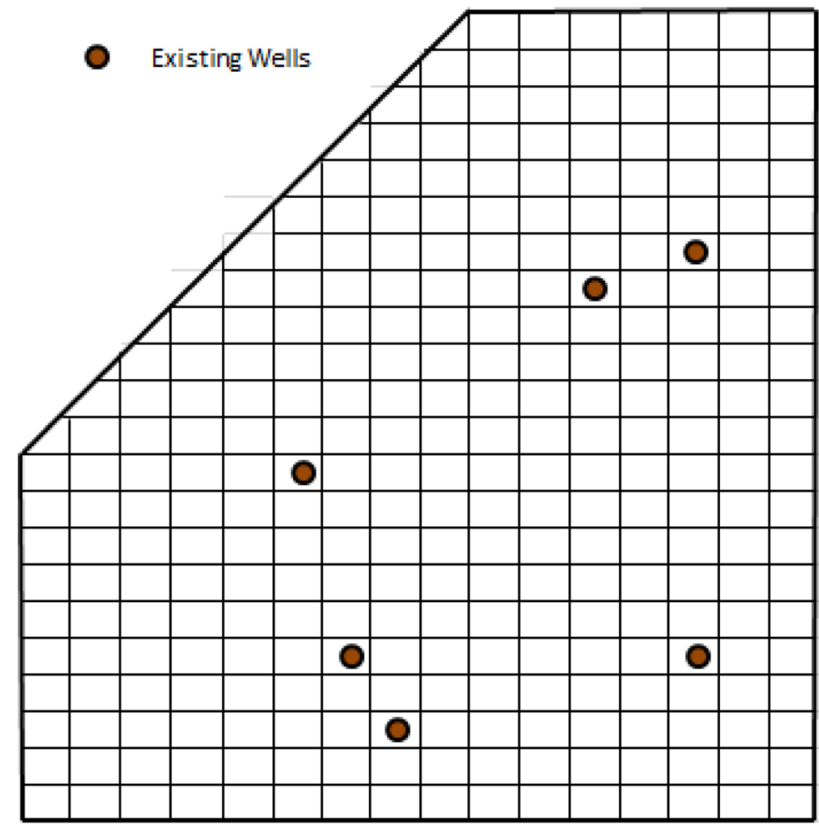

Fig. 7 Locations of existing wells in the reservoir model

additional well. Moreover, the 40-acre spacing is associated with adequate pressure drawdown compared to the 20- and 80 -acre locations. The infill wells located at 40 -acre spacing had lower residual oil saturations compared to the wells placed at 20 -acre and 80 -acre spacing. This can be seen in Fig. 10. However, an optimum pressure was observed for all the three vertical infill wells.

Despite the performance improvement from the infill wells, it is important to note that the 80 -acre infill wells drained more oil than the other wells. The well configuration has high-pressure drawdown and lowest residual oil saturation after extensive production period. We observed high average pressure values in the reservoir at locations of the 80-acre infills (See Fig. 9). After multiple simulation runs, it recorded the highest cumulative oil and gas productions with low cumulative water production profiles as shown in Figs. 11, 12 and 13.

Considering the net present values of the three vertical infill wells, it should be mentioned that the 80 -acre spacing had the highest value. That is $\$ 3.751 \times 10^{9}$ as shown in Fig. 14. The optimized locations for the 80 -acre infill wells are these blocks: $(8,14),(10,9)$ and $(14,10)$. This well configuration could be considered for development of the reservoir because it had the optimum cumulative production and net present value. The 40- and 20-acre infills had net present values of $\$ 3.424 \times 10^{9}$ and $\$ 3.215 \times 10^{9}$, respectively, and the corresponding optimum locations for these well configurations are found in grid blocks: $[(10,7)$, $(10,12),(14,9)]$ and $[(12,7),(12,18),(14,13)]$. The total recovery after initial production with existing wells resulted in oil-in-place of 25.049 MMSTB. After drilling three vertical wells, production of oil in the reservoir peaked at 43.82 MMSTB. This indicates an increase in recovery efficiency from 29.54 to $42.03 \%$ at the end of the simulation.

On the other hand, the potential locations for well placement in example 1 spotted high saturation and pressure areas between the existing wells in the reservoir. This confirms the rising impact of oil production after drilling additional three vertical wells. It is evident that varying the distance between wells to a certain limit resulted in an increase in total hydrocarbon productions, although the optimized locations of the infill wells experienced pressure and saturation variations in the reservoir model.

\section{Case 2: 20-, 40 - and 80-acre spacing for 4 vertical infill wells}

In our decision to improve productivity in the reservoir, we further consider drilling four additional wells as a second

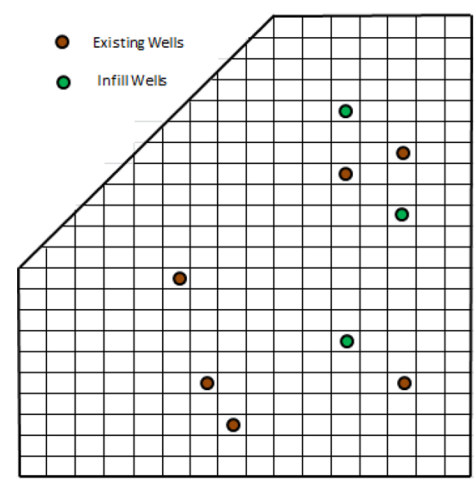

(a) 20 acre well spacing

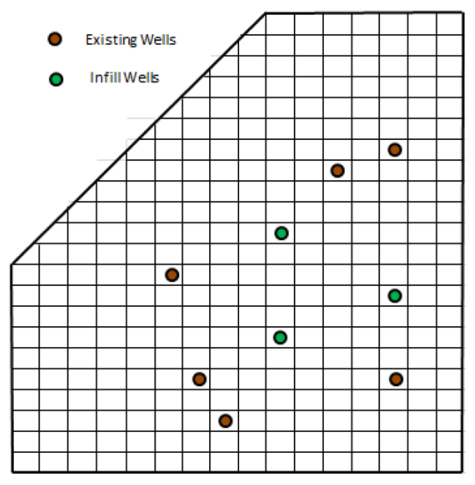

(b) 40 acre well spacing

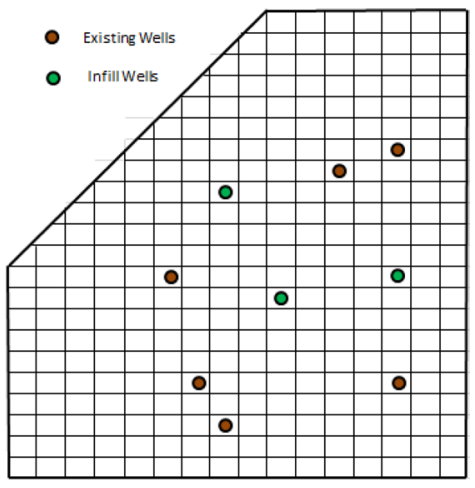

(c) 80 acre well spacing

Fig. 8 Optimized locations for 3 vertical infill wells at different well spacings. Existing wells are indicated by brown color and infill wells indicated by green color 
Fig. 9 Pressure distribution maps for layers of the reservoir with 3 infill wells located at different well spacings (additional 15 years simulated production period)

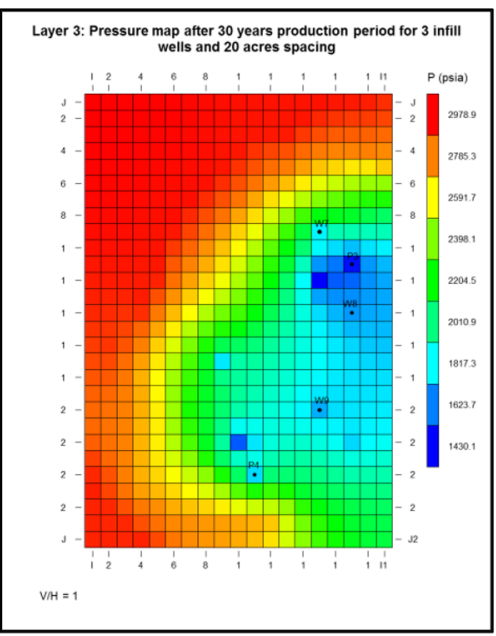

(a) Layer 3 with 3 infill wells at 20 acre spacing

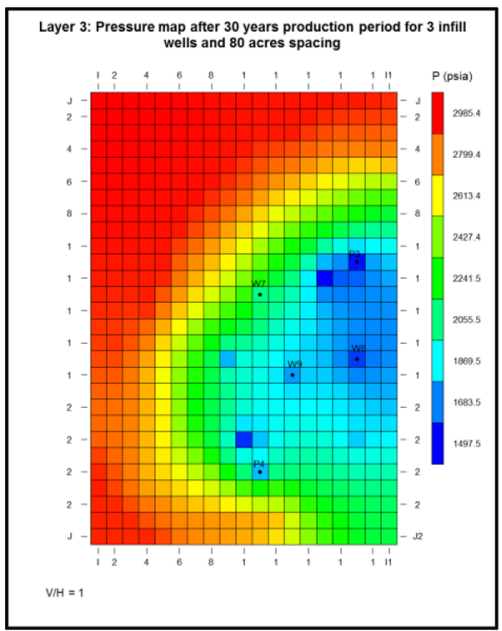

(c) Layer 3 with 3 infill wells at 80 acre spacing

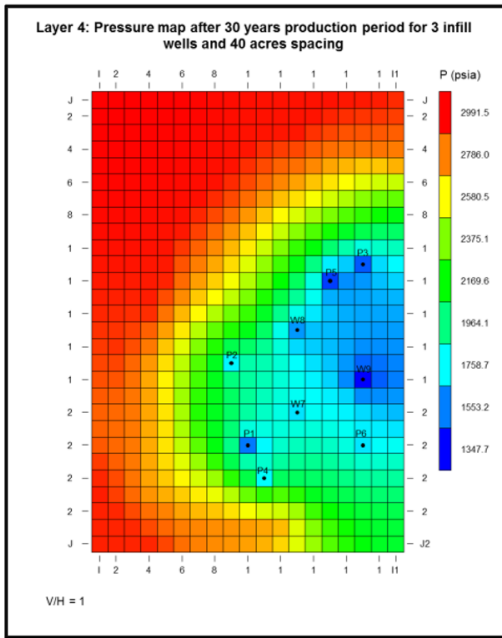

(e) Layer 4 with 3 infill wells at 40 acre spacing

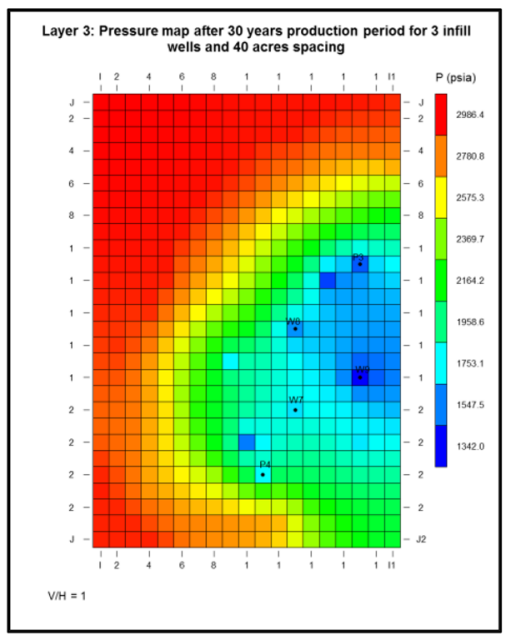

(b) Layer 3 with 3 infill wells at 40 acre spacing

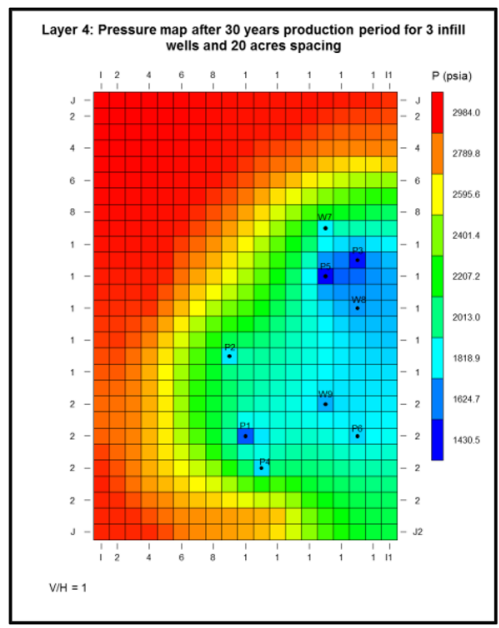

(d) Layer 4 with 3 infill wells at 20 acre spacing

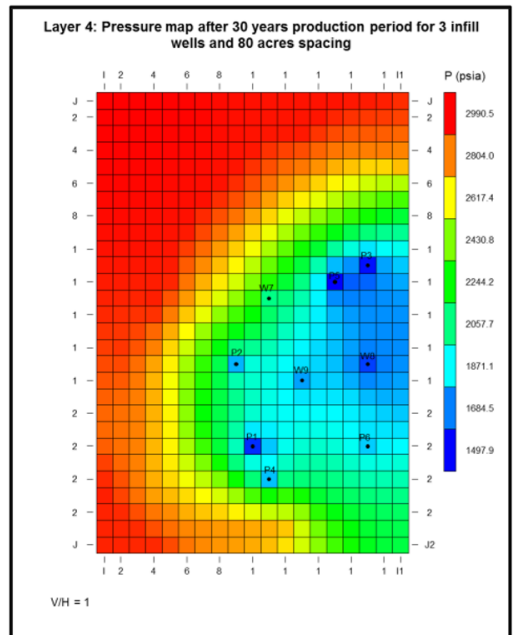

(f) Layer 4 with 3 infill wells at 80 acre spacing case scenario for field development. In this case, four vertical infill wells located at 20 -acre, 40 -acre and 80 -acre spacing were implemented in the reservoir model. Total production time of about 15 years was initiated for simulation to determine optimized locations for the four vertical infill wells. The results of the optimized well locations and the net present values are presented to evaluate the profitability of the reservoir investigated. As an established constraint, we 
Fig. 10 Saturation distribution maps for layers of the reservoir with 3 infill wells located at different well spacings (additional 15 years simulated production period)

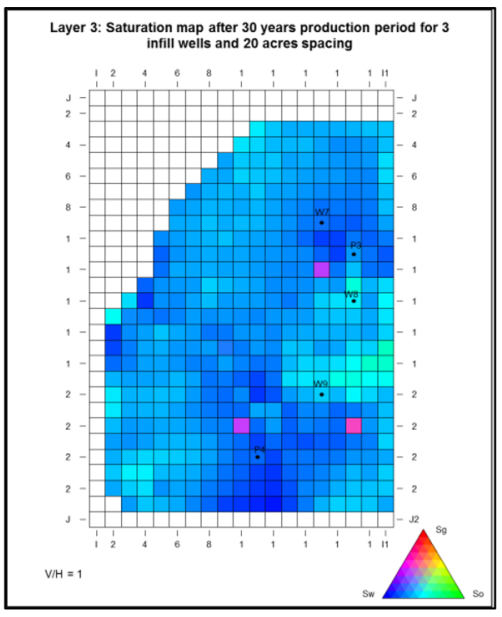

(a) Layer 3 with 3 infill wells at 20 acre spacing

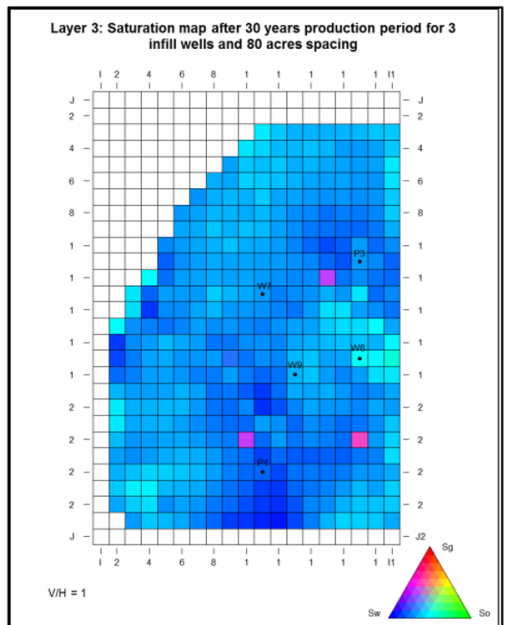

(c) Layer 3 with 3 infill wells at 80 acre spacing

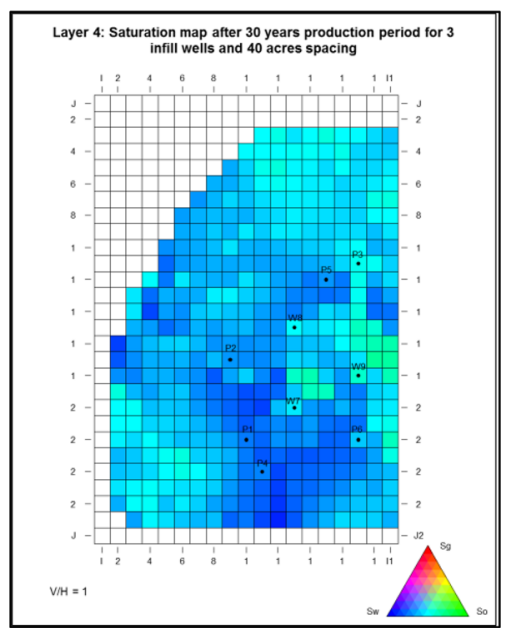

(e) Layer 4 with 3 infill wells at 40 acre spacing

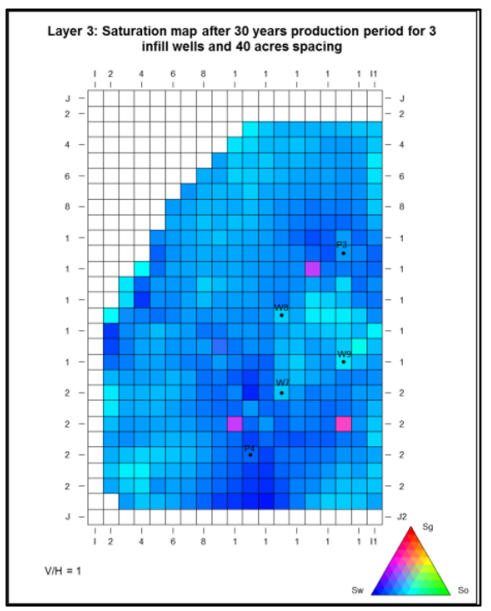

(b) Layer 3 with 3 infill wells at 40 acre spacing

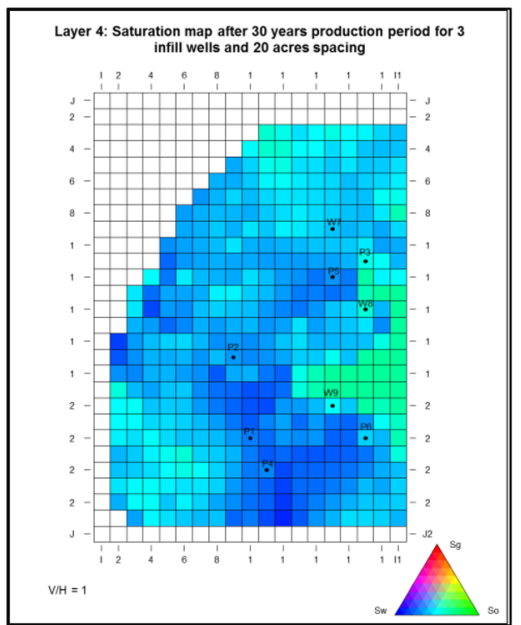

(d) Layer 4 with 3 infill wells at 20 acre spacing

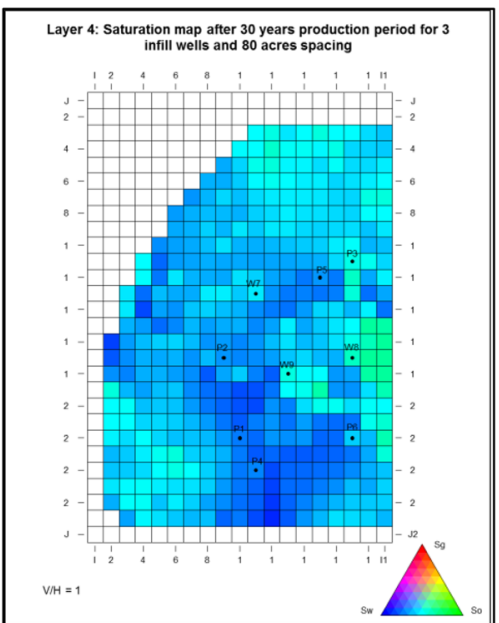

(f) Layer 4 with 3 infill wells at 80 acre spacing also present the pressure and saturation distribution maps for the four vertical infill wells, with respect to maximization of the net present value of the model (See Figs. 16, 17). Figure 15 presents the optimized locations for the 20 -acre, 40 -acre and 80 -acre infill wells. The optimized locations for these wells are seen in the following blocks: $[(8,8),(11,6)$, $(12,18),(14,13)],[(11,5),(9,9),(10,13),(12,19)]$ and $[(10,8),(9,13),(11,19),(14,11)]$, respectively.

Subsequent to determining optimal well locations in the reservoir, infill drilling scenario for the four vertical wells 


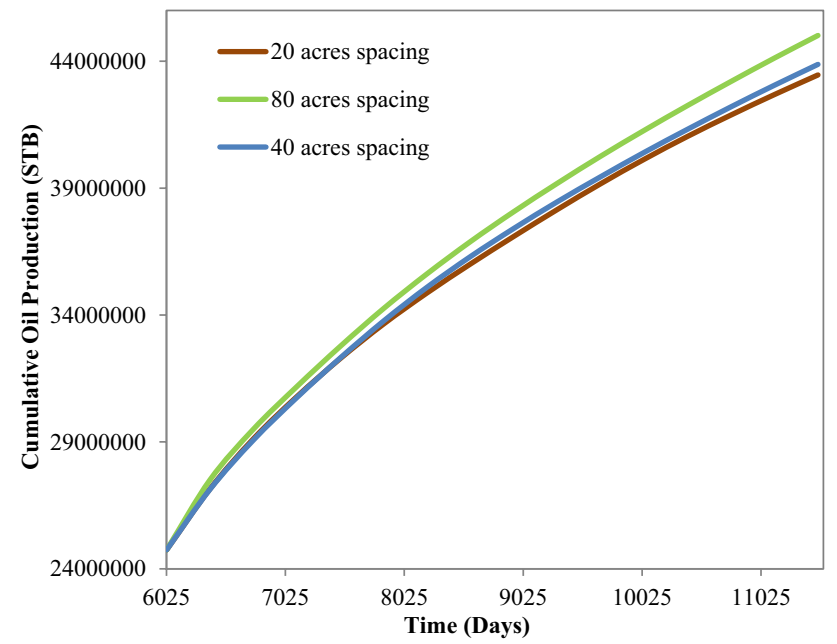

Fig. 11 Cumulative oil production versus time for 3 vertical infill wells at different well spacings

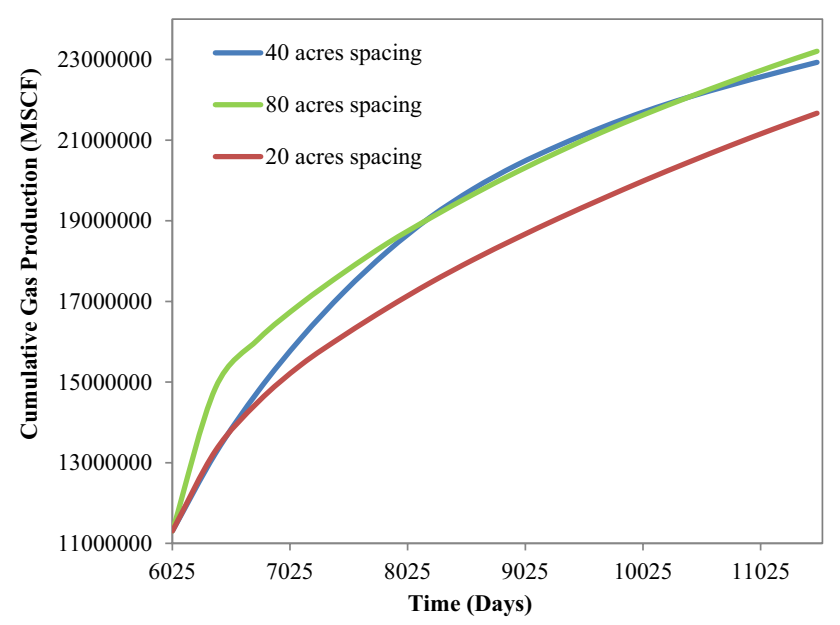

Fig. 12 Cumulative gas production versus time for 3 vertical infill wells at different well spacings

needs to be evaluated. All initial conditions, as well as constraints, are similar to the first infill drilling scenario. After several numerical simulations, the four vertical wells with 40-acre spacing have high-pressure values and least residual oil saturations as shown in Figs. 16 and 17. In this case, there is a higher possibility of experiencing high-pressure drawdown from these wells in the reservoir. Also, we obtained optimum oil and gas recoveries, with the lowest water production from these wells. The cumulative oil, gas and water production profiles are presented in Figs. 18, 19 and 20.

It is evident that the total fluid production increased after drilling the four infill wells (See Figs. 18, 19, 20). The total oil production of the field increased to about 44.0 MMSTB, representing $48.31 \%$ field wide recovery. Consequently, an optimum value of $\$ 3.973 \times 10^{9}$ was obtained for the 40 -acre

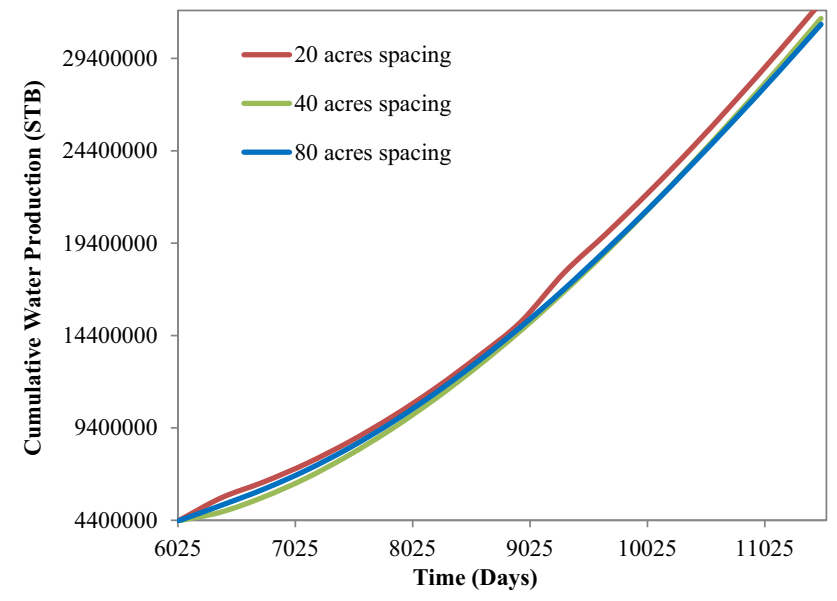

Fig. 13 Cumulative water production versus time for 3 vertical infill wells at different well spacings

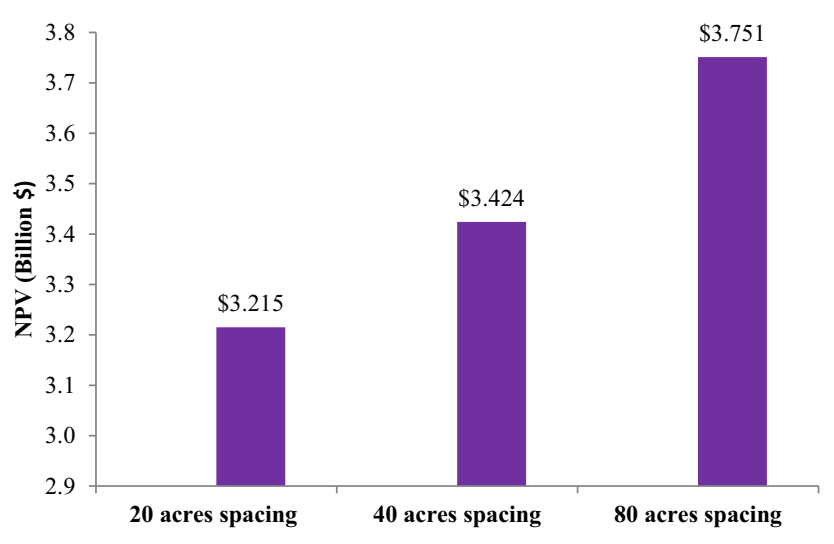

Fig. 14 NPV versus spacing arrangements for 3 vertical infill wells located at different well spacings

infill wells. In addition, the 80 -acre and 20 -acre spacing had net present values of $\$ 3.697 \times 10^{9}$ and $\$ 3.641 \times 10^{9}$, respectively as shown in Fig. 21.

It is therefore appropriate to conclude that the 40-acre spacing targeted high-pressure and oil-saturated areas, resulting in more hydrocarbon recovery and the highest net present value. Likewise, it is economically viable to use this well configuration to enhance productivity in the reservoir.

Although the recovery efficiency from both infill drilling strategies used in this paper gave appreciable results in terms of oil production. However, optimal solutions from the four vertical infill drilling scenario outperform the three vertical infill drilling strategy. The reason behind this rise in NPV is that the best places which are abundant with probable oil production were determined by the second case scenario. The second case scenario increased the recovery factor of about $6.34 \%$ greater than the first case drilling strategy that was implemented. It can be established that the infill drilling

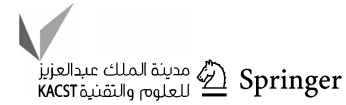




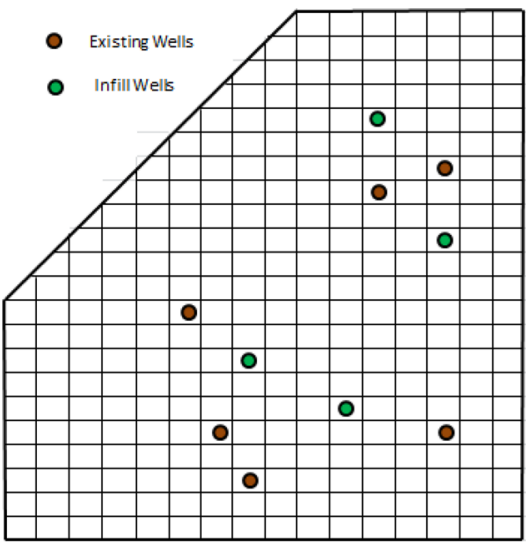

(a) 20 acre well spacing

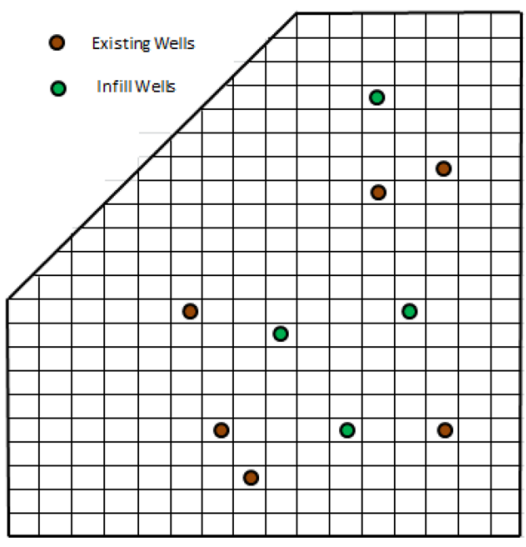

(b) 40 acre well spacing

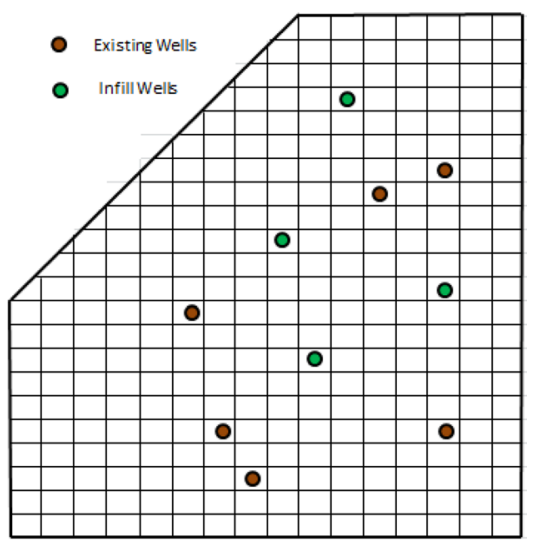

(c) 80 acre well spacing

Fig. 15 Optimized locations for 4 vertical infill wells at different well spacings. Existing wells are indicated by brown color and infill wells represented by green color

scenario has a great influence on increasing the production performance of reservoirs.

Analysis of the results obtained from the simulation outcomes for both cases (Case $1 \& 2$ ) showed that the four vertical infill wells with 40 -acre spacing yield the highest net present value of $\$ 3.973 \times 10^{9}$. Therefore, it is recommended that this infill design be used in developing the reservoir of interest. In brief, it can be stated emphatically that varying the well spacing in relation to the number of wells tends to accelerate the production of hydrocarbons from the reservoir. As a result, feasibility of infill drilling potential is presented to make well-informed decision for selecting the best infill candidate to develop the field.

\section{Uncertainty analysis}

The degree of uncertainties has been a prevailing issue in well optimization problems. Because the optimization variables are usually associated with uncertainties, we consider uncertainty analysis as a criteria to evaluate the petroleum asset. The cumulative fluid production and subsequently, the net present values are directly or indirectly obtained from reservoir and economic parameters that are uncertain. Uncertainties relating to the reservoir and economic parameters were investigated to monitor their impact on the $\mathrm{NPV}$ as the objective function. This provided the platform to evaluate the probability of achieving successful development project for a given infill design. In this paper, the base case values used in the uncertainty analysis were multiplied with high and low values (multipliers) to cover the expected range of uncertainty in the reservoir model and economic variables. Table 5 presents the summary of the economic and reservoir parameters that were varied during the optimization process. The base case values for the reservoir parameters are averaged values in the reservoir model. The base case oil price used is the West Texas Intermediate (WTI) oil price during the period of the analysis (i.e., April/May 2016). The multiplier for the oil price was estimated from the fluctuations in the prices of oil and forecasts made on the oil price. The base case discount rate was obtained as an average value. These multipliers were used to carry out uncertainty analysis on the reservoir model and for determining the net present value of the proposed field development project. The multipliers were varied to obtain the list of runs presented in Table 6. After various simulations were carried out, the probability values assigned to each net present value were obtained. This is presented graphically in Fig. 22.

Figure 22 shows a plot of probabilities against net present values obtained from the uncertainty analysis. It evaluates the economic profitability of the proposed field development project. The net present values at $10 \%, 50 \%$, and $90 \%$ probabilities (i.e., P10, P50, and P90) were estimated to be $\$ 2.83 \times 10^{9}, \$ 3.29 \times 10^{9}$ and $\$ 3.79 \times 10^{9}$, respectively. This implies that there is $90 \%$ probability of achieving $\$ 2.83 \times 10^{9}$ as the net present value. Also, it is probable to make a reasonable net value of $\$ 3.29 \times 10^{9}$. Likewise, there is $10 \%$ probability to earn $\$ 3.79 \times 10^{9}$ for the proposed project.

\section{Summary of discussions and conclusions}

In this study, optimization approach has been proposed for finding suitable locations and spacing between infill wells in a reservoir model. For this approach, the net present value was used as the key objective function for the optimization process. After considering different infill drilling scenarios, the optimum spacing for infill wells was determined for the reservoir model, PUNQ-S3. Using PUNQ-S3 reservoir as the benchmark, the best well configuration was selected for field development. 
Fig. 16 Pressure distribution maps for layers of the reservoir with 4 infill wells located at different well spacings (additional 15 years simulated production period)

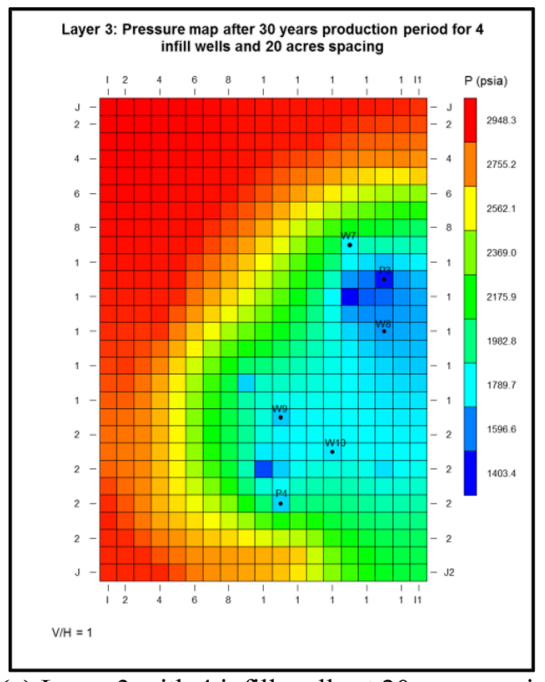

(a) Layer 3 with 4 infill wells at 20 acre spacing

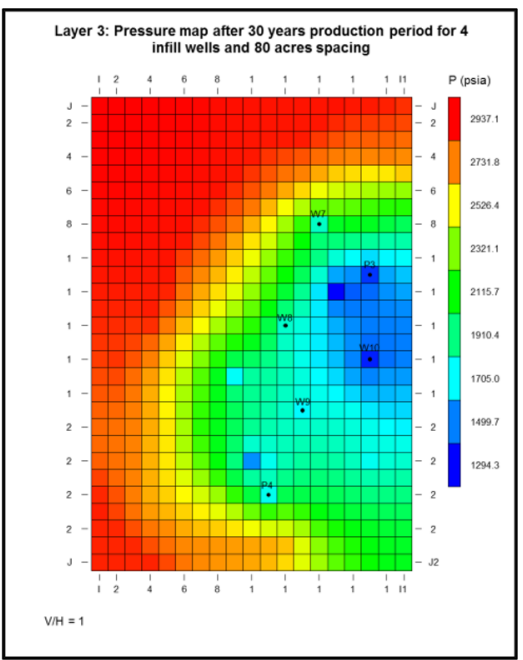

(c) Layer 3 with 4 infill wells at 80 acre spacing

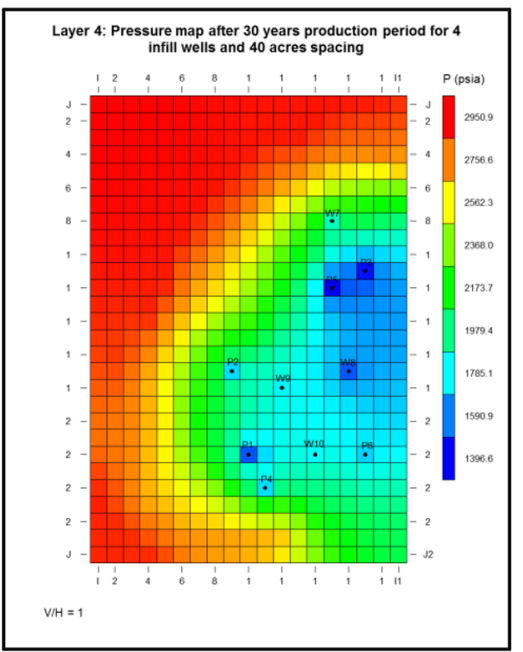

(e) Layer 4 with 4 infill wells at 40 acre spacing

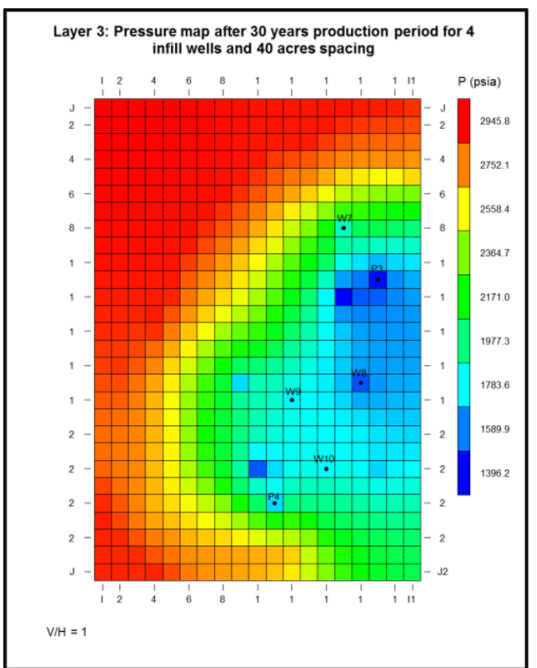

(b) Layer 3 with 4 infill wells at 40 acre spacing

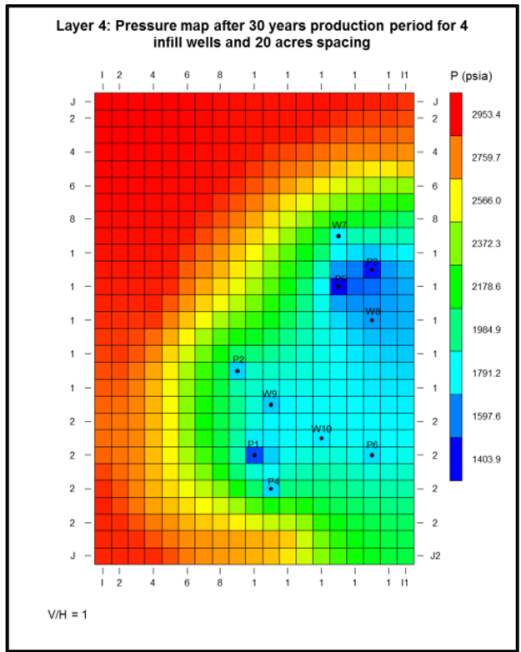

(d) Layer 4 with 4 infill wells at 20 acre spacing

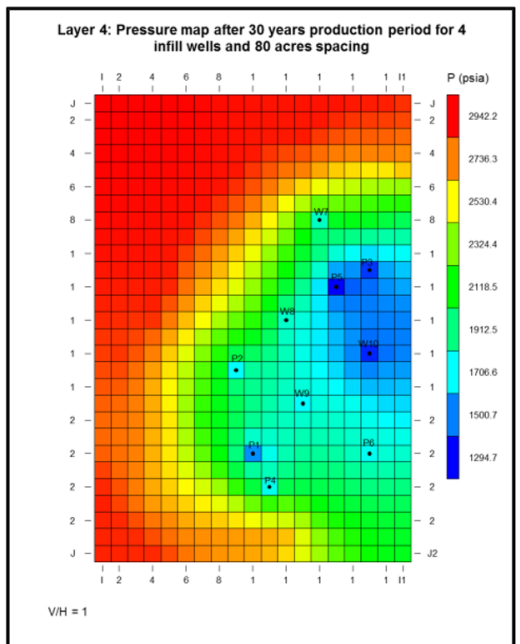

(f) Layer 4 with 4 infill wells at 80 acre spacing 
Fig. 17 Saturation distribution maps for layers of the reservoir with 4 infill wells located at different well spacings (additional 15 years simulated production period)

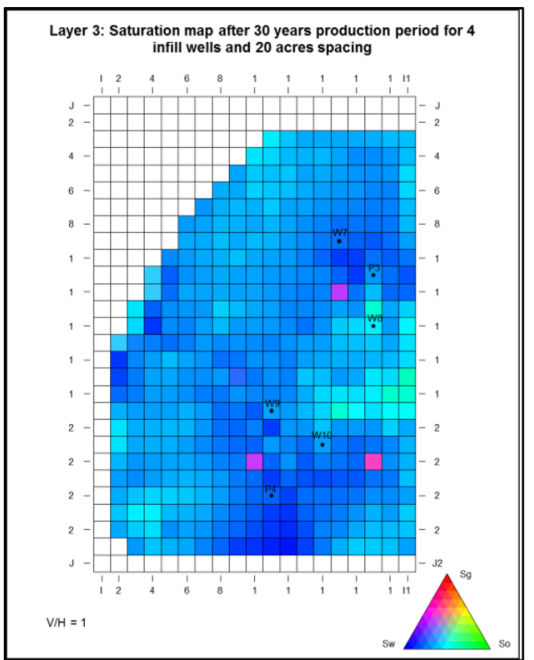

(a) Layer 3 with 4 infill wells at 20 acre spacing

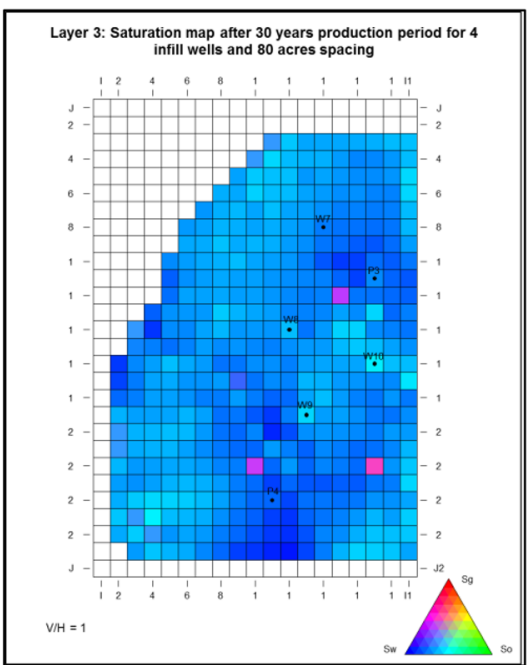

(c) Layer 3 with 4 infill wells at 80 acre spacing

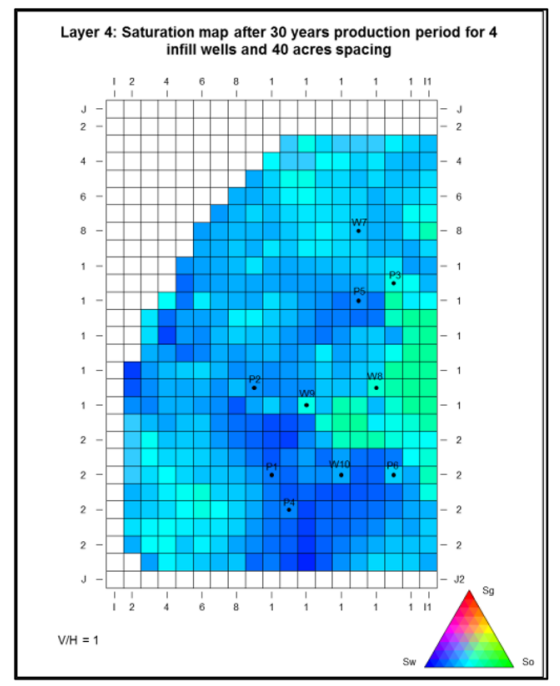

(e) Layer 4 with 4 infill wells at 40 acre spacing

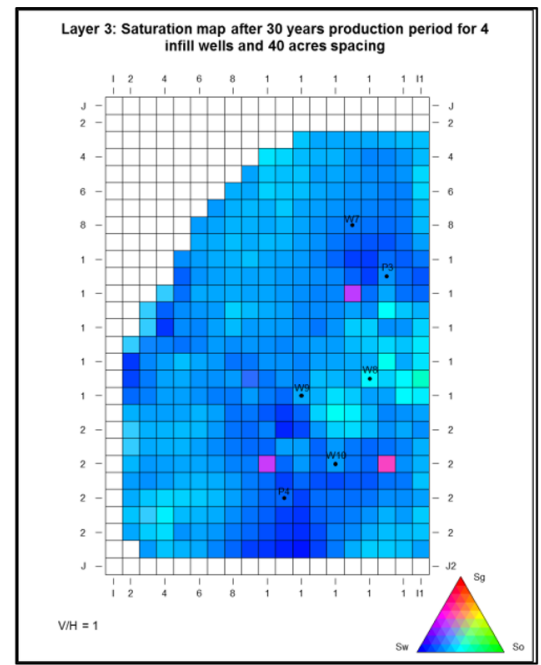

(b) Layer 3 with 4 infill wells at 40 acre spacing

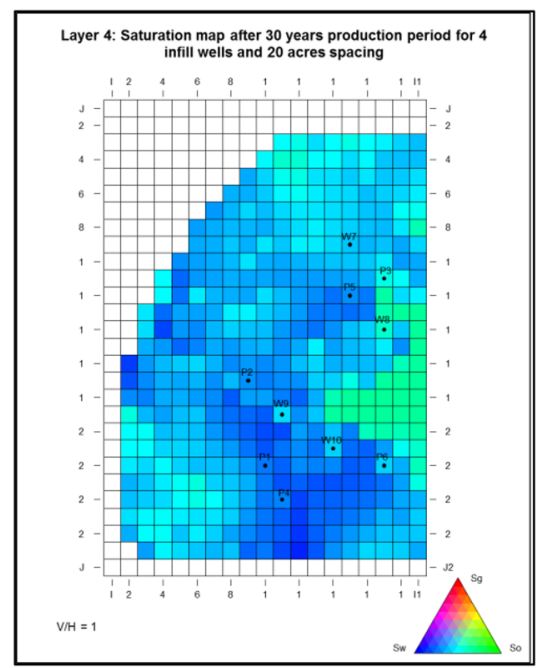

(d) Layer 4 with 4 infill wells at 20 acre spacing

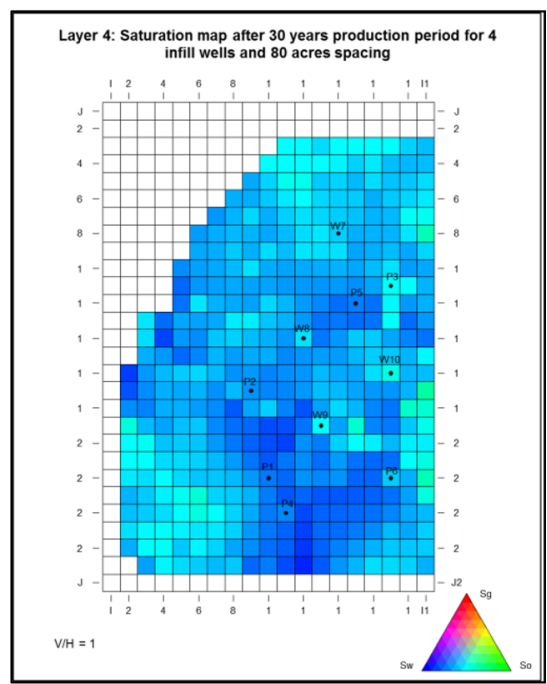

(f) Layer 4 with 4 infill wells at 80 acre spacing 


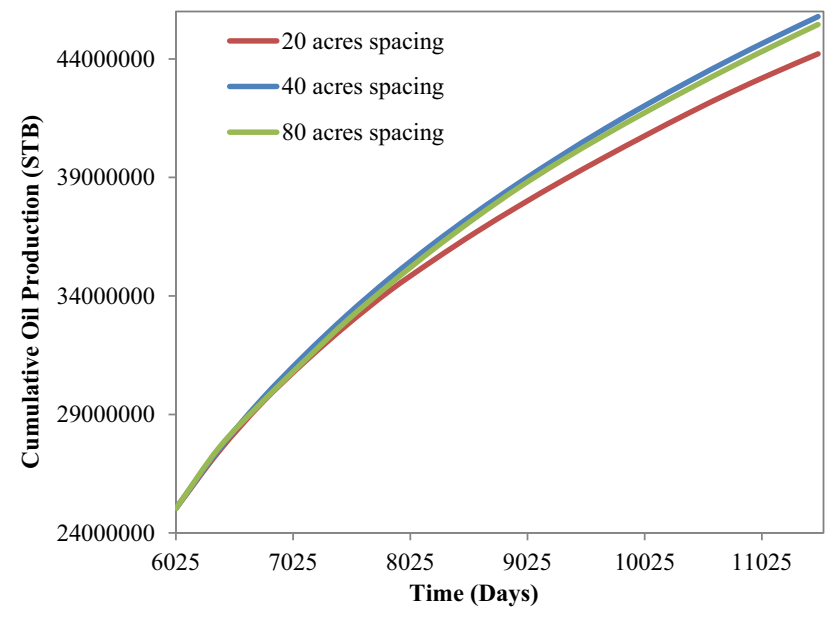

Fig. 18 Cumulative oil production versus time for 4 vertical infill wells at different well spacings

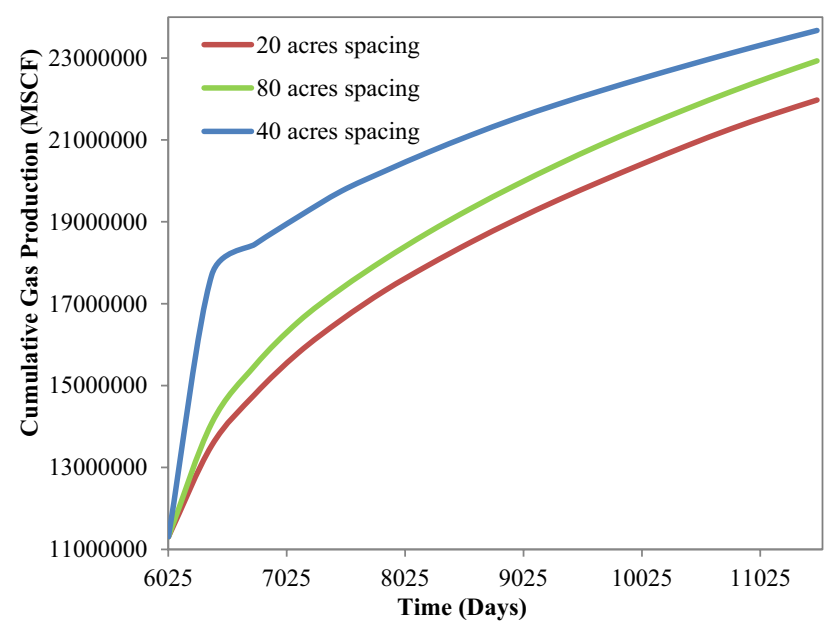

Fig. 19 Cumulative gas production versus time for 4 vertical infill wells at different well spacings

The following conclusions were drawn from the study:

1. The first case drilling scenario showed that the 80-acre spacing infill wells had the highest net value of $\$ 3.751 \times 10^{9}$ in the reservoir model after the optimization process.

2. The 4 vertical infill wells with 40 -acre spacing were selected as the optimum design in the reservoir model. This well configuration predicted the highest net present value in the second case considered. That is $\$ 3.973 \times 10^{9}$. It is therefore recommended that this well pattern be used in developing the studied reservoir.

3. Results from the uncertainty analysis showed possibilities of maximizing the net present values for the different infill designs. Analysis of the 4 vertical infill drill-

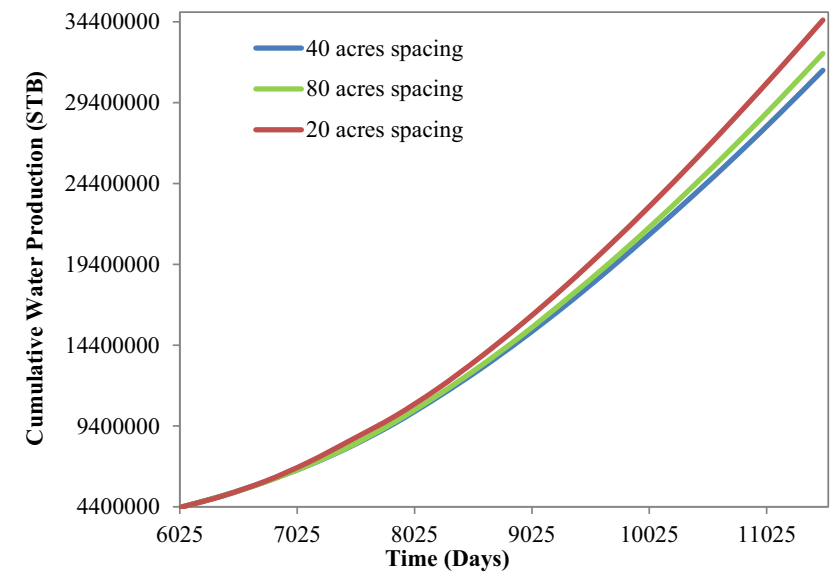

Fig. 20 Cumulative water production versus time for 4 vertical infill wells at different well spacings

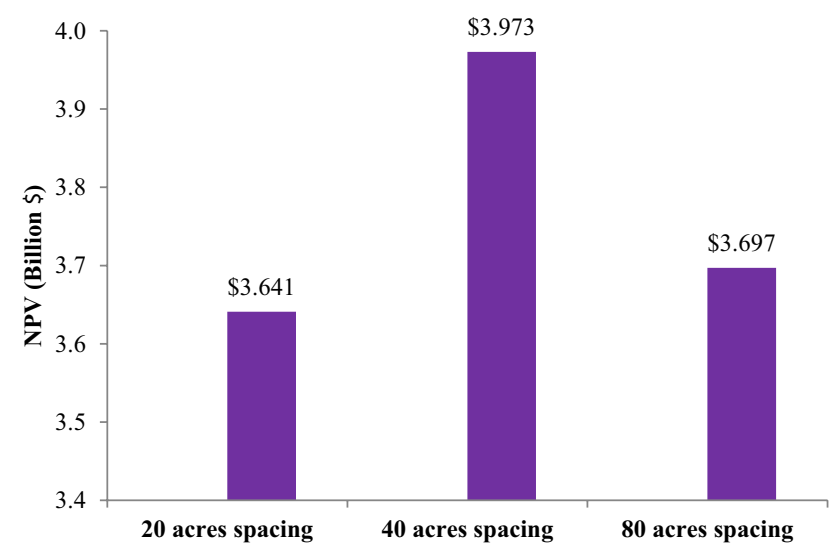

Fig. 21 NPV versus spacing arrangements for 4 vertical infill wells located at different well spacings

Table 5 Summary of the economic and reservoir parameters varied during the uncertainty analysis

\begin{tabular}{llll}
\hline Parameters & Low (multiplier) & High (multiplier) & $\begin{array}{l}\text { Actual/ } \\
\text { average } \\
\text { values }\end{array}$ \\
\hline Oil price & 0.875 & 1.125 & 44.0 \\
Discount rate & 0.800 & 1.20 & 0.10 \\
TranX & 0.800 & 1.20 & 1.00 \\
Poro & 0.900 & 1.10 & 0.187 \\
PermX & 0.720 & 1.25 & 414.6 \\
PermZ & 0.900 & 1.10 & 187.9 \\
\hline
\end{tabular}

ing scenario revealed that there are 10\%, 50\% and 90\% probabilities of attaining the corresponding net present values: $\$ 3.79 \times 10^{9}, \$ 3.29 \times 10^{9}$ and $\$ 2.83 \times 10^{9}$. This demonstrated the efficacy of the optimization program to evaluate the field development. 
Table 6 NPV's and associated probabilities for P10, P50 and P90 estimation

\begin{tabular}{|c|c|c|c|c|c|c|c|c|c|c|c|}
\hline Run No. & $P(x)$ & NPV (Billion \$) & Run No. & $P(x)$ & NPV (Billion \$) & Run No. & $P(x)$ & NPV (Billion \$) & Run No. & $P(x)$ & NPV Billion (\$) \\
\hline 1 & 0.005 & 2.557 & 26 & 0.255 & 3.031 & 51 & 0.505 & 3.287 & 76 & 0.755 & 3.521 \\
\hline 2 & 0.015 & 2.569 & 27 & 0.265 & 3.039 & 52 & 0.515 & 3.292 & 77 & 0.765 & 3.535 \\
\hline 3 & 0.025 & 2.589 & 28 & 0.275 & 3.045 & 53 & 0.525 & 3.307 & 78 & 0.775 & 3.540 \\
\hline 4 & 0.035 & 2.645 & 29 & 0.285 & 3.057 & 54 & 0.535 & 3.310 & 79 & 0.785 & 3.346 \\
\hline 5 & 0.045 & 2.708 & 30 & 0.295 & 3.064 & 55 & 0.545 & 3.321 & 80 & 0.795 & 3.559 \\
\hline 6 & 0.055 & 2.709 & 31 & 0.305 & 3.071 & 56 & 0.555 & 3.341 & 81 & 0.805 & 3.560 \\
\hline 7 & 0.065 & 2.748 & 32 & 0.315 & 3.078 & 57 & 0.565 & 3.348 & 82 & 0.815 & 3.590 \\
\hline 8 & 0.075 & 2.771 & 33 & 0.325 & 3.082 & 58 & 0.575 & 3.366 & 83 & 0.825 & 3.598 \\
\hline 9 & 0.085 & 2795 & 34 & 0.335 & 3.096 & 59 & 0.585 & 3.380 & 84 & 0.835 & 3.621 \\
\hline 10 & 0.095 & 2.809 & 35 & 0.345 & 3.106 & 60 & 0.595 & 3.381 & 85 & 0.845 & 3.659 \\
\hline 11 & 0.105 & 2.828 & 36 & 0.355 & 3.130 & 61 & 0.605 & 3.382 & 86 & 0.855 & 3.661 \\
\hline 12 & 0.115 & 2.842 & 37 & 0.365 & 3.131 & 62 & 0.615 & 3.386 & 87 & 0.865 & 3.670 \\
\hline 13 & 0.125 & 2.846 & 38 & 0.375 & 3.139 & 63 & 0.625 & 3.391 & 88 & 0.875 & 3.702 \\
\hline 14 & 0.135 & 2.858 & 39 & 0.385 & 3.142 & 64 & 0.635 & 3.411 & 89 & 0.885 & 3.708 \\
\hline 15 & 0.145 & 2.866 & 40 & 0.395 & 3.155 & 65 & 0.645 & 3.416 & 90 & 0.895 & 3.733 \\
\hline 16 & 0.155 & 2.883 & 41 & 0.405 & 3.157 & 66 & 0.655 & 3.419 & 91 & 0.905 & 3.801 \\
\hline 17 & 0.165 & 2.899 & 42 & 0.415 & 3.175 & 67 & 0.665 & 3.422 & 92 & 0.915 & 3.804 \\
\hline 18 & 0.175 & 2.907 & 43 & 0.425 & 3.180 & 68 & 0.675 & 3.425 & 93 & 0.925 & 3.840 \\
\hline 19 & 0.185 & 2.917 & 44 & 0.435 & 3.183 & 69 & 0.685 & 3.430 & 94 & 0.935 & 3.845 \\
\hline 20 & 0.195 & 2.940 & 45 & 0.445 & 3.188 & 70 & 0.695 & 3.431 & 95 & 0.945 & 3.901 \\
\hline 21 & 0.205 & 2.958 & 46 & 0.455 & 3.206 & 71 & 0.705 & 3.441 & 96 & 0.955 & 3.944 \\
\hline 22 & 0.215 & 2.982 & 47 & 0.465 & 3.242 & 72 & 0.715 & 3.460 & 97 & 0.965 & 3.950 \\
\hline 23 & 0.225 & 3.006 & 48 & 0.475 & 3.246 & 73 & 0.725 & 3.486 & 98 & 0.975 & 3.983 \\
\hline 24 & 0.235 & 3.007 & 49 & 0.485 & 3.251 & 74 & 0.735 & 3.490 & 99 & 0.985 & 4.044 \\
\hline 25 & 0.245 & 3.021 & 50 & 0.495 & 3.282 & 75 & 0.745 & 3.491 & 100 & 0.995 & 4.093 \\
\hline
\end{tabular}

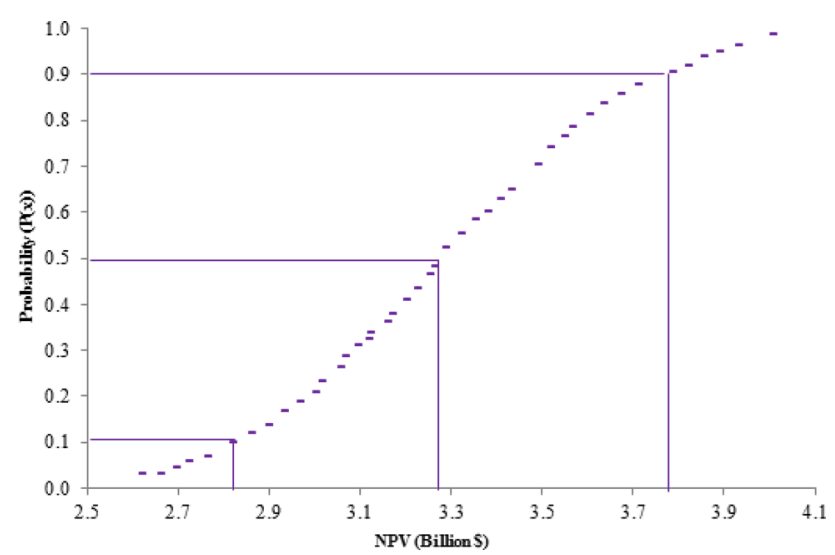

Fig. 22 A graph of probability versus NPV for P10, P50, and P90 estimation

4. Results from the initial production with appraisal wells (i.e., without infill wells) using the optimization approach showed a recovery efficiency of $29.54 \%$. Moreover, the total recovery after second case infill drilling increased to $48.31 \%$, indicating an improvement in oil recovery by $19 \%$ of the initial volume of oil-in-place.
Acknowledgements The authors would like to appreciate the effort of Prof. (Emeritus) David O. Ogbe, for the topic and Coats Engineering, Inc., USA, for donating the Sensor6K simulator used for this research. Also acknowledged are Miss Mavis Acheampong of Assistant Family Group of Companies, Italy, and Dr. Jerome Onwunalu, Stanford University, USA, for their assistance rendered.

Open Access This article is distributed under the terms of the Creative Commons Attribution 4.0 International License (http://creativeco mmons.org/licenses/by/4.0/), which permits unrestricted use, distribution, and reproduction in any medium, provided you give appropriate credit to the original author(s) and the source, provide a link to the Creative Commons license, and indicate if changes were made.

\section{References}

Abukhamsin AY (2009) Optimization of well design and location in a real field. Master's Thesis Report, Energy Resources Engineering Department, Stanford University, USA

Agbauduta EA (2014) Evaluation of in-fill well placement and optimization using experimental design and genetic algorithm. Master's Thesis Report, Petroleum Engineering Department, African University of Science and Technology, Nigeria

Artus V, Durlofsky LJ, Onwunalu JE, Aziz K (2006) Optimization of nonconventional wells under uncertainty using statistical proxies. Comput Geosci 10(4):389-404 
Badru O, Kabir CS (2003) Well placement optimization in field development. Paper SPE 84191 presented at the SPE annual technical conference and exhibition, Denver, Colorado, USA, October 5-6

Bittencourt AC, Horne RN (1997) Reservoir development and design optimization. Paper SPE 38895 presented at the annual technical conference and exhibition by SPE, San Antonio, USA, October $5-8$

Clerc M (2006) Stagnation analysis in particle swarm optimization or what happens when nothing happens. Technical Report CSM-460, Department of Computer Science, University of Essex. Edited by Riccardo Poli

Coats Engineering, Inc. (2013) Sensor compositional and black oil reservoir simulation software. http://coatsengineering.com/senso r_reservoir_simulator.htm. Accessed 12 May 2018

Eberhart RC, Kennedy J (1995) A new optimizer using particle swarm theory. In: Proceedings of the sixth international symposium on micromachine and human science, pp 39-43

Emeric A, Silva E, Messer B, Almeida L, Szwarcman D, Pacheco M, Vellasco M (2009) Well placement optimization using a genetic algorithm with nonlinear constraints. SPE Paper 118808 presented at the SPE reservoir simulation symposium, The Woodlands, Texas, 2-4 February

Engelbrecht AP (2005) Fundamentals of computational swarm intelligence. Wiley, Chichester

Farshi M (2008) Improving genetic algorithms for optimum well placement. Master's Thesis Report, Energy Resources Engineering Department, Stanford University, USA

Goldberg DE (1989) Genetic algorithms in search, optimization and machine learning. Addison-Wesley, Reading
Guyaguler B, Horne RN, Rogers L, Rosenzweig JJ (2000) Optimization of well placement in a Gulf of Mexico Waterflooding Project. SPE Paper 63221 presented at the 2000 SPE annual technical conference and exhibition, Dallas, Texas, October 1-4

Kennedy J, Eberhart RC (1995) Particle swarm optimization. In: Proceedings of the IEEE international joint conference on neural networks, pp 1942-1947, IEEE, December, 1995

Onwunalu JE (2006) Optimization of Nonconventional well placement using genetic algorithms and statistical proxy. Master's Thesis Report, Energy Resources Engineering Department, Stanford University, USA

Onwunalu JE (2010) Optimization of field development using particle swarm optimization and new well pattern descriptions. $\mathrm{PhD}$ thesis, Energy Resources Engineering Department, Stanford University, USA

Shi Y, Eberhart RC (1998) A modified particle swarm optimizer. In: Proceedings of the IEEE international conference on evolutionary computation, May, 1998. IEEE Press, pp 69-73

Yeten B (2003) Optimum deployment of nonconventional wells. Ph.D. thesis, Energy Resources Engineering Department, Stanford University, USA

Yeten B, Durlofsky LJ, Aziz K (2003) Optimization of nonconventional well type, location and trajectory. SPE J 8(3):200-210

Publisher's Note Springer Nature remains neutral with regard to jurisdictional claims in published maps and institutional affiliations. 